Portland State University

PDXScholar

1991

\title{
An investigation of English spelling problems of Arabic-speaking students
}

Deborah Georgette Keim

Portland State University

Follow this and additional works at: https://pdxscholar.library.pdx.edu/open_access_etds

Part of the Applied Linguistics Commons, and the Bilingual, Multilingual, and Multicultural Education Commons

Let us know how access to this document benefits you.

\section{Recommended Citation}

Keim, Deborah Georgette, "An investigation of English spelling problems of Arabic-speaking students" (1991). Dissertations and Theses. Paper 4172.

https://doi.org/10.15760/etd.6056

This Thesis is brought to you for free and open access. It has been accepted for inclusion in Dissertations and Theses by an authorized administrator of PDXScholar. Please contact us if we can make this document more accessible: pdxscholar@pdx.edu. 
AN ABSTRACT OF THE THESIS OF Deborah Georgette Keim for the Master of Arts in Teaching English to Speakers of Other Languages presented June 19, 1991.

Title: An Investigation of English Spelling Problems of Arabicspeaking Students.

APPROVED BY THE MEMBERS OF THE THESIS COMMITTEE:

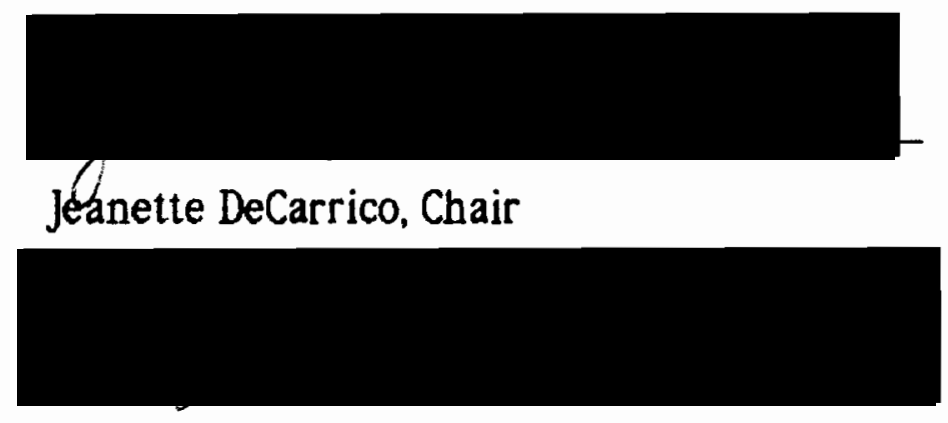

Marjorie Terdal

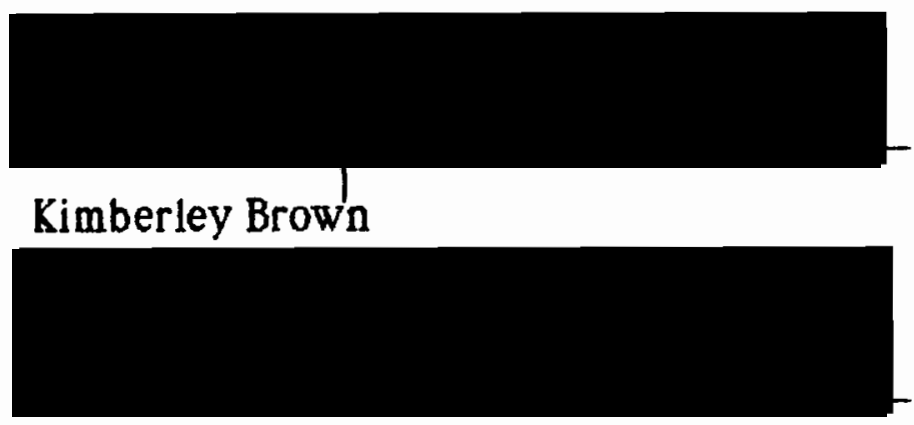

Ray Mariels

In this two-part study, English spelling errors of Arabicspeaking students are investigated. Specifically, an empirical study is done to document and investigate exactly what kinds of English 
spelling errors Arabic-speaking students actually make. Then these data are analyzed, and spelling error patterns are discovered. Next, a study is done to determine if the presence of spelling errors in written work has a significant negative effect on readers' evaluations of this writing.

This study was designed to test three hypotheses in order to answer the following three research questions:

1. What kinds of spelling errors do Arabic-speaking students actually make?

2. Are there some patterns to the English spelling errors of Arabic-speaking students?

3. Do spelling errors in a written English text have a significant negative influence on readers' evaluation of it? Is there a significant relationship between spelling errors in a tert and readers' evaluation of the text?

The hypotheses generated from these questions are the following:

1. Arabic-speaking students make a variety of spelling errors in English.

These errors are discussed in Part One, which is a descriptive study of spelling errors. The actual collection of spelling errors is included as Appendix A.

2. There are patterns to the English spelling problems of Arabic-speaking students.

This hypothesis is supported based on the analysis of spelling error data in Part One, which is a descriptive study. Spelling error patterns are discussed in detail. 
3. (A) Spelling errors in a written English text have a significant negative influence on readers' evaluation of it.

(B) There is a significant difference between the mean scores a reader assigns to a text with spelling errors compared with the same tert with no spelling errors. The scores will be significantly lower for a text that includes various spelling errors, compared with the same text with no spelling errors. These two hypotheses are supported by the results of Part Two of this study. The results suggest that a high density of spelling errors in a text ( 21 to $26 \%$ spelling error density) has a negative influence on readers' evaluation of it. However, a low density of spelling errors in a text ( 7 to $13 x$ spelling error density) does not show a negative influence. There is a relationship between the density of spelling errors in a tert and the scores that evaluators assign to the tert. In this study, the scores were significantly lower for texts that included a high density of spelling errors compared with the same texts with no spelling errors. The scores were not significantly lower for texts with a low error density compared with the same texts with no spelling errors.

The information presented in this thesis offers valuable insights that can increase teachers awareness of the spelling problems of Arabic-speaking students and encourage understanding of why they have these difficulties. Furthermore, this thesis provides empirical evidence that shows the negative influence that a high density of spelling errors can have on readers' evaluation of a written tert. In 
addition, this thesis offers suggestions for helping students improve their spelling ability. It is hoped that spelling practice will be incorporated into TESOL (Teaching English to Speakers of Other Languages) curricula, according to students' needs. 
AN INVESTIGATION OF ENGLISH SPELLING PROBLEMS OF ARABIC-SPEAKING STUDENTS

\author{
by \\ DEBORAH GEORGETTE KEIM
}

A thesis submitted in partial fulfillment of the requirements for the degree of

MASTER OF ARTS

in

TEACHING ENGLISH TO SPEAKERS OF OTHER LANGUAGES

Portland State University

1991 
TO THE OFFICE OF GRADUATE STUDIES:

The members of the Committee approve the thesis of Deborah Georgette Keim presented June 19, 1991.

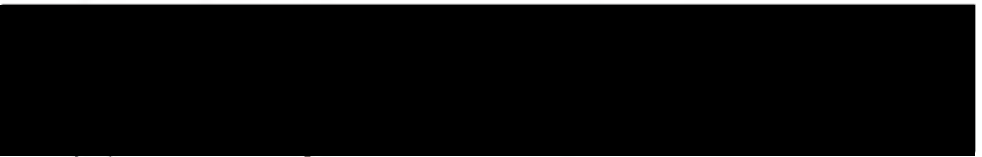

beanette DeCarrico, Chair

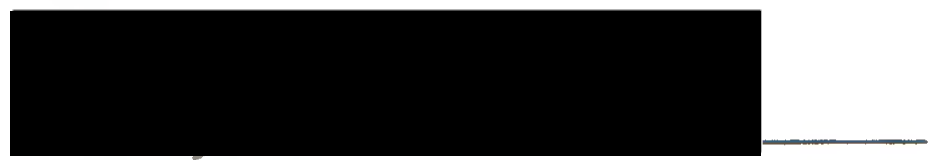

Marjorie Terdal

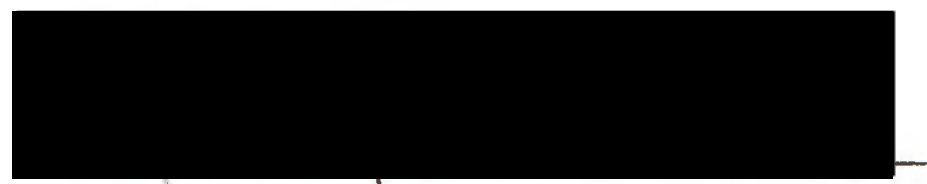

Kimberley Brown

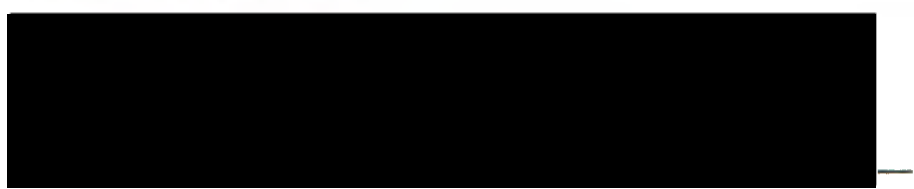

Ray Mariels

APPROVED:

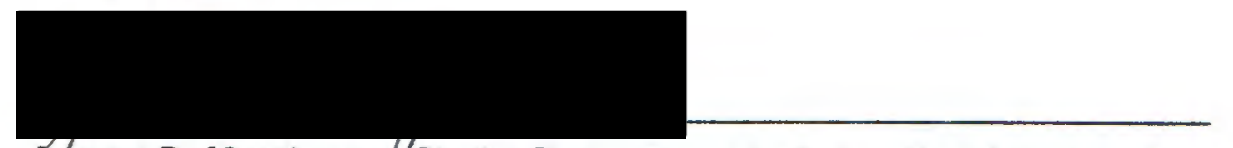

Jafmes R. Nattinger/Chair, Department of Applied Linguistics

C. William Savery, Interim Vice Provost for Graduate Studies and Research 


\section{DEDICATION}

I would like to dedicate my thesis to my family: my mother, Frances Trebelhorn; my grandmother, Georgia Rossos; and my brother, Michael Keim. I appreciate your love and support, and I dedicate this thesis to you.

With Love,

Deb 


\section{ACKNOWLEDGEMENTS}

I would like to acknowledge the members of my committee who offered their help and support with my thesis. I wish to express my sincere gratitude and appreciation to Jan DeCarrico, who acted as both my academic advisor and thesis advisor. I appreciate the guidance and support that she has given me. I want to thank Marge Terdal for her ongoing help and suggestions for my research and thesis. Also, I am grateful to Kim Brown for her support and assistance with my thesis. I wish to thank Ray Mariels for offering his ongoing support and for participating as a member of my committee. I appreciate everyone who helped me with this research project. 


\section{TABLE OF CONTENTS}

PAGE

ACKNOWLEDGEMENTS $\ldots \ldots \ldots \ldots \ldots \ldots \ldots \ldots \ldots \ldots$ iii

LIST OF TABLES $\ldots \ldots \ldots \ldots \ldots \ldots \ldots \ldots \ldots \ldots \ldots \ldots \ldots \ldots$

CHAPTER

I INTRODUCTION $\ldots \ldots \ldots \ldots \ldots \ldots \ldots \ldots \ldots, 1$

Research Questions and Hypotheses ....... 1

Background ...................... 3

Clarification of Terms ................. 4

Summary of Literature ................ 4

Summary ....................... 8

II REVIEW OF THE LITERATURE ................ 10

English Spelling .................... 10

Spelling Problems of ESL Students ..........15

Evaluation of ESL Students' Written Work ..... 17

Spelling Problems of Arabic-Speaking

Learners of English ................... 22

Summary ........................ 29

III METHODS AND PROCEDURES. .............. 31

Summary of Research .................. 31

Research Methodology ................ 32

Subjects .......................... 34

Instruments and Materials ............ 36 
Scoring

Statistical Procedure ............... 41

IV RESULTS $\ldots \ldots \ldots \ldots \ldots \ldots \ldots \ldots \ldots \ldots \ldots \ldots \ldots$

Analysis of the Spelling Error Data . . . . . . . 42

Analysis of the Raters' Scores

for the Six Texts ................. 48

Spelling Error Density . . . . . . . . . . . . 49

V SUMMARY AND DISCUSSION ............. 52

Discussion of Hypotheses ........... 53

Discussion of Results .............. 55

The Importance of this Research Project . . . . . 57

Teaching Suggestions . ............. 58

In Conclusion $\ldots \ldots \ldots \ldots \ldots \ldots \ldots \ldots \ldots \ldots \ldots$

Directions for Further Study . . . . . . . . 62

REFERENCES ............................ 64 APPENDICES

A SPELLING ERROR DATA $\ldots \ldots \ldots \ldots \ldots \ldots \ldots \ldots \ldots$

B SCORING SHEET, SCORING GUIDE, AND TWO VERSIONS OF THE PACKET OF SIX TEXTS

C THE SIX TEXTS WITH SPELLING ERRORS

HIGHLIGHTED . . . . . . . . . . . . . . . . . . . . . 94

D RATERS SCORES .................... 101

E ANNOTATED BIBLIOGRAPHY OF RESOURCES FOR

TEACHING SPELLING . . . . . . . . . . . . . . . 104 


\section{LIST OF TABLES}

TABLE

PAGE

I Organization of Reading Packets ........... 40

II Major Spelling Error Patterns . ............ 43

III Mann-Whitney U Test Results Comparing Texts with Spelling Errors and Texts Without Spelling Errors ... 48

IV Spelling Error Density of the Terts ........... 50 


\section{CHAPTER I}

\section{INTRODUCTION}

In this two-part study, English spelling errors of Arabicspeaking students are investigated. Specifically, an empirical study is done to document and investigate exactly what kinds of English spelling errors Arabic-speaking students actually make. Then these data are analyzed, and spelling error patterns are discovered. Next, a study is done to determine if the presence of spelling errors in written work has a significant negative effect on readers' evaluations of this writing.

\section{RESEARCH QUESTIONS AND HYPOTHESES}

The purpose of this thesis is to investigate the spelling problems of Arabic-speaking students. The three questions this research seeks to address are:

1. What kinds of spelling errors do Arabic-speaking students actually make?

2. Are there some patterns to the English spelling errors of Arabic-speaking students? 
3. Do spelling errors in a written English text have a significant negative influence on readers' evaluation of it? Is there a significant relationship between spelling errors in a text and readers' evaluation of the text?

The hypotheses generated from these questions are the following:

1. Arabic-speaking students make a variety of spelling errors in English.

These errors are discussed in Part One, which is a descriptive study of spelling errors. The actual collection of spelling errors is included as Appendix A.

2. There are patterns to the English spelling problems of Arabic-speaking students.

This hypothesis is supported based on the analysis of spelling error data in Part One, which is a descriptive study.

3. (A) Spelling errors in a written English text have a significant negative influence on readers' evaluation of it.

(B) There is a significant difference between the mean scores a reader assigns to a text with spelling errors compared with the same text with no spelling errors. The scores will be significantly lower for a tert that includes various spelling errors, compared with the same tert with no spelling errors.

These two hypotheses are supported based on the results of the research project done in Part Two. 


\section{BACKGROUND}

"Arabs make lots of spelling errors." "Arabs are bad spellers." These comments are often made by English as a Second Language (ESL) teachers. Many experienced ESL teachers agree with the observation that Arabic-speaking students have ongoing problems with the spelling of English. Arab students do not seem to know what to do to help themselves improve their spelling, and this important area is rarely addressed in ESL programs.

Arab students are often stigmatized because of their spelling problems. In this study, these spelling problems are investigated, and patterns of spelling errors are discovered. This information can be useful for ESL teachers so that they can help these students improve their spelling. The other part of this study investigates how spelling errors in written work affect readers' evaluations. In addition, some directions for further study in these areas are suggested.

Naturally, it is in ESL students' written work that spelling errors will be apparent. When these students are able to do their writing outside of class, they have access to many sources of assistance, such as word processors that check spelling. Native English speakers can proofread students' papers for them, or students can use dictionaries to check spelling themselves. However, when ESL students must do in-class writing, their resources are more limited. Writing assignments that are done in class, such as essay exams and other written assignments, are a reflection of students' spontaneous 
writing ability.

Spelling, of course, is only one aspect of writing ability. Other qualities of written work are important, too, such as organization, content, grammar, and vocabulary. Students' written work may be judged harshly when they have problems in any of these areas.

\section{CLARIFICATION OF TERMS}

The term "Arabic-speaking students" is used for simplicity. To be specific, they are Arab students whose first language is Arabic. In addition to speaking Arabic, they also read and write Arabic.

The English spelling referred to here is Standard American English spelling.

\section{SUMMARY OF LITERATURE}

The spelling of English creates problems for many people, and even native speakers of English encounter difficulties with spelling. Moreover, for non-native users of English, spelling is an especially difficult challenge.

The act of spelling involves a complicated process. "The task is to translate oral words into graphic symbols by means of visual memory and phonetic and motor clues. This is a complex sensorymotor process in which eye, hand and articulatory muscles must all be coordinated so that correct habits can be established" (Hildreth, 1955 . p. 25).

If a reader cannot understand the students' meaning because of 
spelling errors, then this creates a serious communication problem. Sometimes readers can ascertain correct spelling and, therefore. interpret correct meaning despite spelling errors. Other times, readers are unable to make assumptions about the correct spelling of certain words that are spelled incorrectly, and then communication is negatively affected. Correct spelling is not the most important part of good writing ability, but it is definitely an essential part.

Using Burt and Kiparsky's (1972) classification of errors, global errors cause a reader to misunderstand a written message or to find it incomprehensible. Local errors, on the other hand, cause the reader little or no difficulty in comprehension of the message. These two kinds of errors actually form a local error to global error continuum, with errors falling somewhere along this line. Referring to his examination of intermediate ESL students written compositions, Hendrickson (1977) reports that most global errors were a result of insufficient lexical knowledge, incorrect use of pronouns and prepositions, and seriously misspelled words. Furthermore, most local errors were a result of omission or incorrect use of prepositions, absence of subject-verb agreement, problems with lexical choice, and misspelled words. The local errors are not as serious since they cause little or no misunderstanding. However, when misspellings cause an inability to communicate a message and are considered global errors, the problem is very serious.

In a study of teachers' evaluations of written work, Sparks (1988) discovered that the presence of errors in texts influenced readers scoring of them. Similarly, Charney (1984) claims that 
readers' judgments are affected by errors, and he reports that spelling consistently correlates with holistic scores.

However, Freedman (1979) found that the influence of spelling errors did not significantly influence readers' evaluations of an essay when it included a low spelling error density. In fact, this observation agrees with the present study, and the relationship of spelling error density to readers' evaluations of a text will be discussed in the Results section of this thesis.

ESL students of many language groups have problems with the spelling of English. However, students whose native language is Arabic are especially known for having ongoing difficulties spelling well in English. Arab students are often stigmatized because of their written work, with one of the problem areas being spelling. Many language educators suggest that priority should be given to errors that stigmatize learners (Johansson, 1973; Richards, 1973; Sternglass, 1974; Corder, 1975; Hanzeli, 1975; Birckbichler, 1977). Even though many educators make this recommendation, little attention is given to Arab students' spelling problems. Unfortunately, these students carry their problem and its stigma along with them as they participate in regular academic classes.

There is not much literature in the ESL field regarding spelling. There is even less literature on spelling with respect to Arabicspeaking learners of English. One journal article that does address this issue is "Patterns in Spelling Errors." In this article, Ibrahim (1978) classifies the spelling errors in the written work of a group of Arab learners of English, and offers possible explanations for these errors. 
His data come from the written work of Arab undergraduate students of English at the University of Jordan. Ibrahim suggests the following categories for the spelling errors he observed: Errors caused by 1) the non-phonetic nature of English spelling, and 2) differences between the sound systems of English and the learners' native language, Arabic; errors which may be 3) attributed to analogy, 4) attributed to the somewhat inconsistent and arbitrary nature of English word derivation, and 5) described as transitional; 6) errors caused by differences between British and American English spelling conventions; and 7) items which defy categorization, possibly due to confusion, fatigue, carelessness, or a similar factor (pp. 209-212).

Thompson-Panos and Thomas-Ruzic (1983) add an additional category to this list: "Errors caused by differences in the orthographic representation of the common vowel sounds in the two languages" (pp. 611-612). In fact, this category is appropriate as a subcategory of Ibrahim's number two above. Category number two could be divided into the consonant sound system and the vowel sound system.

Ibrahim's study is extremely valuable since it is almost the only work that has been done in this area which is lacking in research. Spelling is a neglected area of study, and the spelling problems of Arabic speakers is a subject nearly totally ignored in the available research. While Ibrahim's article is significant and his effort commendable, his classification system does not seem appropriate for an experimental study. Regarding the classification of spelling errors into these categories, Ibrahim himself explains: "In the absence of 
experimental evidence the assignment of many errors to certain categories remains arbitrary. One can do little more than guess at the underlying cause of an error" (p. 212, italics added). Ibrahim's system is speculative and untestable. He can assume the underlying cause of an error, but there is no way to test this. An alternative classification system is used in Part One of this study. (This is described in detail in the Methods and Procedures section below.)

Thompson-Panos and Thomas-Ruzic (1983) believe that knowledge of the Arabic language and familiarity with some of the contrasting features of written Arabic and English can be helpful when considering the written work of Arabic-speaking students. In this article, they discuss the spelling problems of Arab students.

Some journal articles include a discussion of spelling problems of Arabic-speaking students, but most of these articles seem to be either poorly written or based on questionable studies. More thorough explanations of these studies are needed. (These articles are discussed in depth in the Review of the Literature section.)

\section{SUMMARY}

This research project is a two-part study of the spelling errors of students whose native language is Arabic. Part One is a descriptive study. This part involves a collection of spelling error data and an analysis and classification of the data. Spelling errors are analyzed and classified according to error type, then the data are compiled and patterns are determined. The second part is a study to determine if 
the presence of misspellings in a tert has a significant negative influence on the scores given to the text by evaluators.

From this research project, some valuable, concrete information about the spelling errors of Arabic-speaking students is discovered. the influence of spelling errors on evaluators' scores is investigated, and teaching suggestions and directions for further study in this area are offered. 


\section{CHAPTER II}

\section{REVIEW OF THE LITERATURE}

This section surveys the available literature that relates to spelling problems of Arabic-speaking learners of English. This survey begins with a discussion of English spelling in general, then it focuses on spelling problems of English as a second language (ESL) students. After this, a discussion of the evaluation of ESL students' written work is presented. Next, the specific focus is on the spelling errors of those ESL students whose native language is Arabic, and writings on the spelling problems of Arabic-speaking students are discussed.

\section{ENGLISH SPELLING}

The spelling of English creates problems for many people, including native speakers of English. Moreover, for non-native users of English, spelling is an especially difficult challenge. Unfortunately, spelling problems can have a negative effect on students' attitudes towards writing. As Hildreth observes, "People who feel insecure in spelling of ten hesitate to write" (1955, p. 2).

The act of spelling involves a complicated process. "The task is to translate oral words into graphic symbols by means of visual 
memory and phonetic and motor clues. This is a complex sensorymotor process in which eye, hand and articulatory muscles must all be coordinated so that correct habits can be established" (Hildreth, 1955. p.25). When spelling, one must rely on "visual memory and auditorymotor-graphic associations" (Hildreth, p. 25).

Many elements play a part in learning how to spell, according to Hildreth. The spelling process includes:

hearing the sounds in words and distinguishing between the sounds in similar words, getting clear-cut visual impressions of word forms and distinguishing similar words visually, matching sound elements to the graphic symbols representing them in words that are phonetically consistent, and pronouncing words accurately and syllabicating correctly. (p. 25)

There are many reasons for spelling troubles in English. In her book Teaching Spelling, Hildreth points out some of the sources of difficulty (pp. 4-5):

1. The same letter or letter combination may have alternative sounds. This is especially true of vowels, but also true of some consonants and diphthongs. Hildreth suggests that they are forty-four basic sounds in English, with twenty-three letters of the alphabet to symbolize them. She doesn't include the letters "c," "y," and "x" because she considers these "duplicates."

2. The same sound can be shown in a variety of ways, using different letters or combinations of letters. For example, Hildreth claims that there are fourteen different letters or letter combinations to represent the long " 0 " sound. 
3. Silent, unsounded letters occur in many English words. Hildreth asserts that of the 600,000 words in Webster's Unabridged Dictionary more than 400,000 include one or more silent, unsounded letters.

4. Homonyms and words with alternate spellings can cause confusion.

Even though there seem to be many sound-grapheme deviations, the English language is, in fact, approximately eighty-five percent phonetic, according to Hildreth (1955). Hodges and Rudorf (1966) also claim that "large numbers of words have relatively consistent phoneme-grapheme (sound-to-letter) relationships" (p. 29). In spite of the mostly systematic nature of English spelling, the teaching of spelling is often based on the assumption that there is not much relationship between the sound and the spelling of words, so that each word is treated as an individual item to be learned (Hodges and Rudorf, 1966).

Woifram and Johnson (1982) report that most of the languages in the world employ writing systems that directly correspond to their phonology. In these languages, orthographic symbols represent phonological units of the language. English is one of these languages. However, many linguists and educators disagree about how phonology is represented in the English system. The popular belief is that English is inconsistent, illogical, and irregular. However, Wolfram and Johnson assert that "although the system certainly reveals complexities in its organization, English is hardly the haphazard, illconceived system that it has been made out to be" (p. 198). Patterns 
of symbol-sound correspondence exist in English, and this information is extremely valuable for understanding English orthography. This knowledge can greatly improve ESL teachers' ability to help students, especially Arab students, with their English spelling problems.

Wolfram and Johnson (1982) explain that no strictly phonetic alphabetic systems exist, but some spelling systems can be considered phonemic, that is, "a different alphabetic symbol--usually labeled a grapheme--is used to represent each distinct phoneme in the sound system" (p. 198). Arabic can be described as a phonemic language, according to this description. However, the orthographic representation in English is obviously not a correspondence of one letter representing one phonological unit since there are 26 letters in the English written alphabet and, according to some analyses, over 40 phonemes in the language. In addition to the 26 letters, there are many digraphs, letter pairs that represent a single unit of sound. Furthermore, symbols do not have to be directly adjacent to each other, as in the vowel + consonant + final (silent) "e" pattern, in order to be significant. Also, distribution within words can affect which orthographic symbol is used to represent a sound.

English spelling is a complicated process. Wolfram and Johnson (1982) observe that:

quite clearly, the patterning of correspondence between graphic symbols and sound units involves more than single graphic symbols. Surrounding graphic symbols, phonological context, and information from the syntactic/semantic levels of language must all be considered in determining the regular patterns of English orthography. (p. 201) 
The distribution of graphemes, including their positioning, sequencing, and combinations, must be considered in order to determine the regular correspondence patterns in English orthography. Phonological context must also be considered, such as the distribution of stress in words. According to the regular rule in English, vowels are reduced in unstressed syllables, but surrounding segments can also influence symbol-sound relationships.

The majority of the symbol-sound relationships in English are variant correspondences, according to Wolfram and Johnson (1982). One symbol does not always correspond to a specific sound unit. They claim that "the symbol-sound relationships are regular in the sense that they are predictable, but the phonological value of the symbols changes as a result of graphic, phonological, or grammatical conditioning" (p. 203). Regularity means that a symbol-sound relationship can be predicted nonarbitrarily by a learner of the system, and cues from the system can help to predict correspondences. While there are some cases of symbol-sound irregularity in English, the majority are regular.

So far this discussion has dealt with the decoding process, or the symbol-to-sound relationship, required for reading. However, spelling requires an encoding, sound-to-symbol correspondence. While Wolfram and Johnson explain that there are more predictable patterns in the symbol-to-sound correspondence, they also assert that there is more predictability than is usually believed in the sound-to-symbol spelling process. They say that "English is still not an easy language to 
spell" (p. 204), but spelling ability can be improved by using systematic information about sound-to-symbol correspondences. It is important "for educators to concentrate on understanding the extensive patterning that does exist in the current system and the various subsystems that have been incorporated into it" (p. 207). Based on this suggestion, it seems that one way teachers can help students improve their spelling ability is to explicitly teach them the regular spelling patterns that do exist in English.

\section{SPELLING PROBLEMS OF ESL STUDENTS}

Unfortunately, as Wolfram and Johnson (1982) note. "orthographies are not designed for foreigners. For the most part. they are designed for native speakers, and thus take advantage of the kinds of knowledge native speakers have about their phonology" ( $p$. 198). But even many native speakers of English have serious spelling problems. If people who have been using English all of their lives continue to have difficulty with spelling, then what must it be like for learners of English as a second language? Spelling difficulties are apparent in ESL students' written work at all proficiency levels. Not only is English spelling a problem area for these students while they are in English language programs, but spelling continues to be difficult for them when they enter regular academic classes.

Hildreth (1955) presents some learning principles that influence spelling (pp. 26-27, italics added). In response to each of these principles, a brief explanation is given specifically relating to ESL 
students:

"Learning is, in part, a sesuft of imitation."

Many ESL students have limited English language experience and. therefore, need more practice imitating correct spelling.

"Trial and error is a part of learning 10 spell."

Again, many ESL students have not had much chance to to experience trial and error related to English spelling.

'Students' attitudes and emotions about words, school, and even the teacher can afrect Jearning to spell!."

ESL students may have strong attitudes and experience intense emotions, not only related to English words, school, and their teachers. but also towards the new culture, the use of English as a second language, and the experience of being away from their countries.

Learning to spell is related to other kinds of linguistic progress, Hildreth claims. She believes that a student who "tends to be less competent in oral language and slow in learning to read tends to be slow in learning to spell" (p. 27). Speaking and writing are interrelated: Words used in speaking are often the words used in writing. Furthermore, accurate pronunciation is important for correct spelling, and students with articulation difficulties may encounter problems.

Unfamiliarity with words may be a cause of spelling errors. Hildreth notes that "a low meaning vocabulary is likely to be a cause of spelling difficulty. Children have a hard time even copying a word that is unknown to them in context" (p. 28). She refers here to children, but this seems to apply to ESL students, as well. 
If students are not familiar with certain words, it may be difficult for them to spell these words correctly. Ibrahim (1978) suggests that "the fact that a student cannot spell a certain word correctly may indicate that he may not have learned this word well enough to be able to spell it" (p. 212).

Other factors can influence spelling, too. Ball (1986) argues that perceptual and motor skills are inertricably connected, and problems with the English graphic system may influence inaccuracies in spelling caused by attempts to hurry or by carelessness.

\section{EVALUATION OF ESL STUDENTS' WRITTEN WORK}

Written work is of ten given a score for its overall quality, that is, a letter grade. A grade is assigned for the piece of writing as a whole, based on the overall impression it makes on the reader. Charney (1984) refers to this as a "General Impression Marking" (p. 68). But Sparks (1988) observes that this type of scoring:

is subjective and impressionistic by its very nature, and that even the most controlled 'calibration' of raters would not prevent certain inconsistencies and disagreements. Despite these shortcomings, this impressionistic form of grading is a frequently used method of evaluating writing. (p. 33)

Therefore, the importance of correct spelling depends on the weight that an individual teacher wishes to assign to it.

Charney (1984) claims that the reason single scores for overall 
writing quality are reliable is that they "reflect agreement on salient but superficial features of the writing, such as the quality of the handwriting or the presence of spelling errors" (p. 78, italics added). In order for these scores to reflect substantive writing skill, superficial features must not influence the validity of the ratings. Charney believes that more research is needed to determine how strongly spelling influences these ratings for overall quality. This is the research goal that is undertaken in Part Two of this study.

Freedman (1979) investigated how certain characteristics of students' essays influence instructors' evaluations. She conducted a study in which raters judged essay quality using a four-point scale. The original essays were written by English-speaking college students. Essays were rewritten to be strong or weak in four categories: content; organization; sentence structure; and mechanics, which included spelling. An essay classified as "weak" in mechanics included four to five spelling errors per page, a fairly low spelling error density, and it is not stated whether these were local or global errors. In her study, content and organization were found to affect ratings the most. Freedman speculates that "because the influences of sentence structure and mechanics are neither as strong nor as consistent as the influences of content and organization, raters are probably less conscious of the effects of these less important influences" (p. 335). While these findings suggest that spelling errors did not have a significant negative influence on readers' ratings, this is probably because of the low spelling error density of the terts. This aspect of 
Freedman's study is consistent with the results of the present research project, and the relationship of spelling error density to readers' ratings of texts is discussed in the Results section.

Some teachers may judge spelling errors very critically, while others may not give them as much importance. However, spelling errors are often readily apparent as we read, and, therefore, may be easily observed as a problem. Charney (1984) asserts that in order for ratings for overall writing quality to be considered valid, it is important for readers to not be influenced by superficial features of the written work. Spelling errors would fit this description. Mocolly (1970) suggests that essays be typed before they are rated. The effects of neatness and handwriting are reduced this way. Following this suggestion, in Part Two of this study, when subjects are asked to rate written texts, the passages are typewritten, not handwritten.

Furthermore, if a reader cannot understand the students' meaning because of spelling errors, then this creates a serious communication problem. Sometimes readers can ascertain correct spelling and, therefore, interpret correct meaning from spelling errors. Other times, readers are unable to make assumptions about the correct spelling of certain words that are spelled incorrectly, and then communication is negatively affected. Correct spelling is not the most important part of good writing ability, but it is definitely an essential part.

Using Burt and Kiparsky's (1972) classification of errors, global errors cause a reader to misunderstand a written message or to find it incomprehensible. Local errors, on the other hand, cause the reader little or no difficulty in comprehension of the message. These 
two kinds of errors actually form a local error to global error continuum, with errors falling somewhere along this line. Referring to his examination of intermediate ESL students' written compositions, Hendrickson (1977) reports that most global errors were a result of insufficient lexical knowledge, incorrect use of pronouns and prepositions, and seriously misspelled words. Furthermore, most local errors were a result of omission or incorrect use of prepositions, absence of subject-verb agreement, problems with lerical choice, and misspelled words. The local errors are not as serious since they cause little or no misunderstanding. However, when misspellings cause an inability to communicate a message and are considered global errors, the problem is very serious.

Sparks (1988) uses a three-level error tabulation system for the error analysis in his study. Regarding spelling errors, his model describes first-degree, second-degree, and third-degree errors. These descriptions come from Nas (1975, pp. 16-21). Spelling errors are considered first-degree errors when "deviation from correct spelling is minor, a reader has no trouble recognizing the word." Spelling errors are described as second-degree errors when there is "serious deviation from correct spelling; word interpretable in contert." Spelling errors are classified as third-degree errors when the misspelling "makes it impossible to be certain about the word that is meant." Considering local and global errors, it seems that these three degrees fall on a continuum, with first-degree errors being local, second-degree errors being more serious but still local, and third- 
degree spelling errors clearly global errors.

For Sparks' study (1988), two experienced ESL teachers rated the Test of Written English (TWE) essays of thirty college-level ESL students. The findings of this study clearly show that "frequency and seriousness of error was a major factor in evaluators' perceptions of ESL writing quality" (p. 83). As a result of his study showing the major role that errors played in readers' ratings, Sparks makes two comments: First, he observes that it was not encouraging that raters considered errors to be so important in their ratings. Sparks maintains that many other criteria are also important, such as organization, focus, development, vocabulary, coherence, and syntar. Sparks argues that "the essay must be evaluated as a complete act of discourse and not as the sum of its errors" (p. 87). Second, the fact that errors are judged so harshly might mean that teachers should spend more time on analysis and self-correction of errors, and work on "those areas which may allow for rapid progress, such as spelling" (p.86, italics added).

Charney (1984) cites a number of studies that have correlated various characteristics of texts with the single ratings of overall quality that were assigned to them. He claims that "readers' judgments are strongly influenced by salient, though superficial, characteristics of the writing samples" (p. 75). Charney says that there may be high statistical reliability of these ratings because they depend on characteristics that are easy to notice, but do not reflect actual writing ability. Furthermore, he claims that spelling is a factor that consistently correlates with ratings assigned for overall writing 
quality.

It seems that many ESL programs give little attention to the improvement of students' spelling ability. Spelling appears to be a low priority when compared with the many necessary skills that ESL students need to acquire. But because students rarely receive any kind of formal assistance with their spelling problems, this often continues to be an area of frustration for them. As Ibrahim explains, "the foreign learner ... is rarely exposed to a systematic treatment of spelling rules. Instead, he is left to infer these rules by himself" (1978, p. 211). Even if a student does learn spelling rules, if they are learned without their exceptions, the learning of the rule is not complete, and spelling errors will result.

Ball (1986) asserts that students who have difficulties with the graphic structure of English may encounter many writing problems. Inaccuracies in spelling may be caused when students attempt to hurry their writing.

\section{SPELLING PROBLEMS OF ARABIC-SPEAKING LEARNERS OF ENGLISH}

ESL students of many language groups have problems with the spelling of English. However, students whose native language is Arabic are especially known for having ongoing difficulties spelling well in English. Arab students are often stigmatized because of their written work, with one of the problem areas being spelling. Many language educators suggest that "errors that stigmatize the learner from the perspective of native speakers should be among the first 
corrected" (Johansson, 1973; Richards, 1973; Sternglass, 1974; Corder, 1975; Hanzeli, 1975; Birckbichler, 1977). Even though many educators make this recommendation, little attention is given to these Arab students' spelling problems. Unfortunately, they carry their problem and its stigma along with them as they participate in regular academic classes.

There is not much literature in the ESL field regarding spelling. There is even less literature on spelling with respect to Arabicspeaking learners of English. One journal article that does address this issue is "Patterns in Spelling Errors." In this article, Ibrahim (1978) classifies the spelling errors in the written work of a group of Arab learners of English, and offers possible explanations of the reasons for these errors. His data come from the written work of Arab undergraduate students of English at the University of Jordan. Ibrahim suggests the following categories for the spelling errors he observed (pp. 209-212):

1. Errors caused by the non-phonetic nature of English spelling.

2. Errors caused by differences between the sound systems of English and the learners' native language. Arabic.

3. Errors which may be attributed to analogy.

4. Errors which may be attributed to the somewhat inconsistent and arbitrary nature of English word derivation.

5. Errors which may be described as transitional.

6. Errors caused by differences between British and American spelling conventions.

7. Items which defy categorization, possibly due to confusion, fatigue, carelessness, or a similar factor. 
Thompson-Panos and Thomas-Ruzic (1983) add an additional category to this list: "Errors caused by differences in the orthographic representation of the common vowel sounds in the two languages" (pp. 611-612).

Ibrahim found consistent patterns in the spelling errors that he analyzed. He admits that these errors had to be classified according to assumption and speculation, however: "In the absence of experimental evidence the assignment of many errors to certain categories remains arbitrary. One can do little more than guess at the underlying cause of an error" (Ibrahim, p. 212).

Thompson-Panos and Thomas-Ruzic (1983) believe that knowledge of the Arabic language and familiarity with some of the contrasting features of written Arabic and English can be helpful when considering the written work of Arabic-speaking students. In their article "The Least You Should Know About Arabic: Implications for the ESL Writing Instructor," they discuss the spelling problems of Arab students. They present an interesting observation made by Beck (1979):

Spelling errors constituted the single most common error found in a study of freshman compostitions at the University of Petroleum and Minerals in Saudi Arabia. In fact, errors in spelling were so pervasive that ninetyeight percent of all paragraphs examined contained at least one spelling error, with the majority containing many more. (p. 611)

Of course, these students are in an English as a foreign language (EFL) situation, but, nonetheless, this illustrates the seriousness of the 
spelling problems that Arabic-speaking students have.

From their experience in the ESL classroom. Thompson-Panos and Thomas-Ruzic observe that Arabic speakers are often inconsistent in their representation of vowels in English. They claim that "the systems for representing vowels in the two languages lack close correspondence" (p. 612). For example, a student may alternately spell his name "Mohamad" or "Mohamed," and his records may show his name as "Mohammad." In Arabic, his name is represented as "mhmd" (the " $m$ " is doubled), with no vowels shown orthographically.

In fact, there are six vowels in Modern Standard Arabic, a short and long version of the vowels $/ a /, / i /$, and $/ u /$. Long vowels are shown in writing, but short vowels are not, except in certain texts. Thompson-Panos and Thomas-Ruzic claim that "the conventions for vowel representation [in Arabicl have important implications for spelling in English" (p. 612).

Thompson-Panos and Thomas-Ruzic also refer to the fact that much of written Arabic is spelled without vowels. It is their observation that Arab students of ten omit vowels in written English. These authors note that the English vowel system is complex and of ten distinguishes between eleven or more distinctive vowel phones, but uses only sir vowel graphs (including " $y$ ") in writing. They explain that "the meaningful vowel variations found, for example, in beat, bit, bait, bet, pot, bat, bought, boat, put, but, boot, and bout can be difficult for the Arab to discriminate in listening, speaking, and reading, as well as in writing" (Thompson-Panos \& Thomas-Ruzic, p. 
612). Yorkey (1979) explains that before Arab students are able to produce these unfamiliar sounds, they must first be able to recognize them. These sounds, which are distinct sounds in English, are allophonic variants to the Arabic speaker. Joy (1985) believes that in addition to learning new vowel pronunciations and distinctions which may be unclear in Arabic, Arab students must pay a lot of attention to vowel insertion in English writing.

Some transliterated Arabic words demonstrate the absence of a vowel correspondence with English: Muslim and Moslem, Qur'an and Koran, and Muhammad and Mohammed (Thompson-Panos \& Thomas-Ruzic). To help with these spelling difficulties, Arabicspeakers can benefit from a systematic presentation of the spoken English vowel variations and their common representations in writing, Thompson-Panos and Thomas-Ruzic suggest. Furthermore, pointing out the relationship of spelling to word families, roots, and derivations can help students see the regular patterns that do exist in the orthography of English. Schane (1970) agrees that families of related words need to be taught systematically, as well as rules for deriving alternative pronunciation from the same spelling patterns.

Arabic is considered a phonemic language: Each letter represents one sound. However, when learning English, Arabicspeaking students must get used to a language which is inconsistently phonemic. Furthermore, according to Lehn and Slager (1959), Arabic speakers have difficulty with the segmental phonemes of English because of:

(1) differences in the number of contrasts, (2) differences in the permissible sequences, and (3) differences in the 
phonetic expression of 'similar' contrasts. English has many more vowel contrasts, and more consonant contrasts in the labial to velar region than Arabic. (p. 33)

In addition, English allows longer, more complex consonant sequences in initial, medial, and final positions. "All of these differences constitute a major (although not the only) source of difficulty for the speaker of Arabic learning English" (Lehn \& Slager, 1959, p. 33). Obviously, these differences may cause problems in speaking, which probably influence spelling, as well.

Judging by their titles, it seems that certain journal articles will include a discussion of spelling problems of Arabic-speaking students, but then they do not follow through. Hutchinson (1984) wrote an article entitled "Some Predictable Errors of Arab Students in Written English," which was published in IEAM, the journal of the English Language Center at the University of Petroleum and Minerals in Dhahran, Saudi Arabia. He mentions many of the common errors that Arab students make in their written work. However, he fails to mention spelling problems, except to include "Sp" in his error analysis key, indicating a spelling error.

Another article that appears in TEAM "Common Problems in Teaching Writing, Spelling and Pronunciation to Arab Students," is a blatant plagiarism by Lewis (1984), copied nearly verbatim from Thompson-Panos and Thomas-Ruzic's article. It is a sloppy, unethical attempt and simply a rehash of other people's writing. He offers no ideas of information of his own, and even worse, plagiarizes others' work. 
In another TEAM article, "Spelling Tips for Teachers," Tesdell (1984) describes the method and results of a spelling approach that was used with the students in two writing classes at the University of Petroleum and Minerals in Dhahran, Saudi Arabia. The students were given a spelling dictation pretest at the beginning of a three-week period. For each week, students practiced the spelling of ten words on a special spelling worksheet, then they took a spelling dictation test of those words at the end of each week. Finally, at the end of the threeweek period, students took a spelling dictation of all thirty words as a post-test. Tesdell reports that the initial results were encouraging. Pretest scores ranged from seven to fifty-three percent, typically in the twenty to thirty percent range. Post-test scores ranged from fifty to one-hundred percent, with the most frequent score in the nineties. Two students scored one-hundred percent on the post-test. No mean scores are given. Tesdell gives only a brief (one-page) description of this study, but this work has potential for further research.

Finally, in another TEAM journal article, Natusch (1984) claims that the results of two ten-minute spelling quizzes correlated highly with the results of six examinations in different English skill areas. The subjects were Arab students at the University of Petroleum and Minerals in Saudi Arabia. As a result of finding a "highly significant correlation ( $p<.01$ )" (p. 14), Natusch explains that "put simply, this means that spelling test scores are likely to be a good indicator of a student's general proficiency in the scientific/technological English taught in the ELC [English Language Center] course" (p. 14). The 
method and results of this study are questionable since only scanty details are given, and Natusch makes strong assumptions from these results. He goes on to say that this high correlation possibly "indicates that a student who learns his English well also learns to spell" (pp. 1415). This is a strong claim based on dubious results. In conclusion, he suggests that this spelling test is one possible instrument for predicting students' performance on their examinations in this English program. This article is only a two-page summary, and a more thorough explanation of the study is needed.

\section{SUMMARY}

The spelling of English involves a complicated process and creates problems for many people, and even native speakers of English encounter difficulties with spelling. Moreover, for non-native users of English, spelling is an especially difficult challenge.

If a reader cannot understand the students' meaning because of errors, this creates a serious communication problem. Regarding types of errors, Burt and Kiparsky (1972) classify errors as global errors, which cause a reader to misunderstand a written message or to find it incomprehensible, or as local errors, which cause the reader little or no difficulty in comprehension of the message. Referring to his examination of intermediate ESL students' written compositions, Hendrickson (1977) reports that one of the causes of global errors was seriously misspelled words, and one of the causes of local errors was misspelled words. 
Freedman (1979) found that the influence of spelling errors did not significantly influence readers' evaluations of an essay when it included a low error density. However, in a study of teachers' evaluations of written work. Sparks (1988) discovered that the presence of errors in texts influenced readers' scoring of them. Similarly, Charney (1984) claims that readers' judgments are affected by errors, and he reports that spelling consistently correlates with holistic scores.

ESL students of many language groups have problems with the spelling of English. However, students whose native language is Arabic are especially known for having ongoing difficulties spelling well in English. Unfortunately, there is not much literature in the ESL field regarding spelling, and there is even less literature on spelling with respect to Arabic-speaking learners of English. One author who does address this issue is Ibrahim (1978), who classifies the spelling errors in the written work of a group of Arab learners of English and offers possible explanations for these errors. Thompson-Panos and Thomas-Ruzic (1983) also investigate the spelling problems of Arabic speakers, and they believe that knowledge of the Arabic language and familiarity with some of the contrasting features of written Arabic and English can be helpful when considering the written work of Arabicspeaking students. Other journal articles include a discussion of spelling problems of Arabic-speaking students, but more thorough explanations of these studies are needed. 


\section{CHAPTER III}

\section{METHODS AND PROCEDURES}

\section{SUMMARY OF RESEARCH}

This research project is a two-part study. Part One is a collection of spelling error data from the written work of students whose native language is Arabic. Upon completion of data collection, the spelling errors are analyzed and patterns and possible reasons for spelling errors are determined.

Citing areas for further research, Hendrickson (1987) mentions that researchers need to investigate the degree of stigma that native speakers attach to orthographically deviant forms, that is, misspellings, that nonnative learners produce frequently in their writing. Part Two of this study addresses this issue by examining native speakers' ratings of passages that are free of spelling errors compared with the same passages that include spelling errors.

In Part One of this research project, spelling error data, taken from authentic writing samples of Arabic-speaking students enrolled in English as a Second Language (ESL) Programs in Oregon were collected and analyzed (see Appendix A for the corpus). These were existing writing samples that had been kept on file and were provided 
by the directors of these programs.

Part Two of this study explores the effect of the presence of spelling errors in a written text on readers' evaluation of the text. A questionnaire was used (see Appendix B), and forty-four subjects participated in the evaluation of a packet of six authentic texts. Each subject received a packet of six texts to score using a standardized scoring scale. These texts are taken from the writing samples obtained for the spelling error data, as described above, and complete anonymity is guaranteed to the writers. There are two versions of the text packet, each with the same six texts, but with a different combination of texts free of spelling errors and texts with spelling errors.

The evaluators scored each text using the Test of Written English (TWE) sir-point Scoring Guide (included below). The evaluators' scores were then analyzed to determine if the scores for the written passages that included spelling errors were significantly lower than the scores for the written passages that were free of spelling errors.

\section{RESEARCH METHODOLOGY}

For Part One, spelling error data were collected from writing samples of Arabic-speaking students enrolled in various ESL Programs in Oregon. Ibrahim (1978) did a similar data collection in which he collected spelling errors from the written work of undergraduate students in the Department of English at the University of Jordan. This written work included examinations, homework assignments. 
papers, reports, and so on. Ibrahim does not say how many writing samples were examined nor how many spelling errors were collected. For the present study, 311 examples of spelling errors from a variety of sources were collected. This seemed to represent a good sample of spelling errors. These spelling errors were randomly selected from the writing samples collected from the three college ESL programs. The writing samples are authentic in-class writing assignments produced by Arabic-speaking students in ESL programs.

The nert phase of Part One is an analysis of the spelling error data. Each error is described according to type of error: deletion, insertion (epenthesis), metathesis (transposition), or substitution. These terms are appropriate because they accurately describe the spelling errors that occur in the spelling error corpus. These terms are also used to describe phonological processes (Wolfram \& Johnson, 1982). After describing the errors according to type, the findings are analyzed, and spelling error patterns are discovered. The results of this collection and analysis are discussed in the Results section of this thesis.

Citing areas for further research, Hendrickson (1987) mentions that researchers need to investigate the degree of stigma that native speakers attach to orthographically deviant forms, that is, misspellings, that nonnative learners produce frequently in their writing. Part Two of this study explores the issue of the effect of spelling errors in a written text on readers' evaluation of the text.

First, a pilot study was done. The subjects were a group of 
twenty-sir TESOL (Teaching English to Speakers of Other Languages) Methods students. Each subject received a packet of six authentic written texts to evaluate. There were two versions of the text packet, each with a different combination of texts: some texts included misspellings and some were free of misspellings. Each packet had the same six texts, but there was a different combination of texts with spelling errors and texts without spelling errors. Nothing else was corrected in the spelling-error-free, or "clean," texts except the spelling errors. The packets were numbered from 1 to 26 . The oddnumbered packets included this combination of texts ("clean" means corrected for spelling errors, and "errors" means including spelling errors): Text 1 - clean, Text 2 - clean, Text 3 - errors, Text 4 - clean, Text 5 - errors, and Text 6 - clean. The even-numbered packets included the opposite combination of the same six texts: Text 1 errors, Text 2 - errors, Text 3 - clean, Text 4 - errors, Text 5 - clean, and Text 6 - errors. The evaluators' scores were then analyzed to determine if the scores for the written passages that included spelling errors were significantly lower than the scores for the written passages that were free of spelling errors.

SUBJECTS

The subjects for this research project were ESL instructors and writing instructors at two Oregon colleges. A total of 61 subjects 
received text packets to score, but only 44 packets were returned (a 72* response rate).

Before the actual study was done, a pilot study was done. The subjects for the pilot study was a group of twenty-six students enrolled in a Teaching English to Speakers of Other Languages (TESOL) Methods class. Results of the pilot study were used to design the actual research project. The procedures for the actual study, such as the best method of statistical analysis and the number of subjects needed for statistical significance, were based on the findings of the pilot study.

Subjects for Part Two of this project were recruited to complete the questionnaire and evaluate the packet of six texts by contacting the ESL program directors and a writing department director at two Oregon colleges. Subjects were then asked if they would be willing to complete the questionnaire and were told that it would take only about fifteen to twenty minutes. Requests were made either verbally by the director or in written form attached to the packet.

This group of subjects was chosen because they are familiar with the evaluation of students' writing. McColly (1970) believes that "the more competent the judges of essays are the more they will agree and the more valid will be their judgments" (p. 150). By competence, Mccolly means scholarship, or knowledgeability.

Regarding the amount of time spent scoring essays, McColly (1970) claims that increased speed in rating results in increased validity and reliability: 
If a reader is competent, and if he has been well-trained and oriented, his instantaneous judgment is likely to be a genuine response to the thing for which he is looking. But if he is given time to deliberate, he is likely to accommodate his judgment to tangential or irrelevant qualities which will introduce bias into the judgment. (p.74)

In this study, subjects were asked to read the sir texts, then score them according to the TWE Scoring Guide. The scores assigned according to raters' immediate reactions are believed to be reliable and valid judgments.

\section{INSTRUMENTS AND MATERIALS}

In Part Two of this study, six authentic texts are used, and two versions of each text are typed. The version that includes spelling errors is typed verbatim from the original student text, and the version that is without spelling errors is presented verbatim except that the spelling errors are corrected. The texts were selected to provide samples that vary in subject matter, total number of words, and total number of spelling errors. Text 1 is a 176-word text with 12 spelling errors, Text 2 is a 126 -word text with 32 spelling errors, Text 3 is a 101-word text with 26 spelling errors, Tert 4 is a 160 -word text with 14 spelling errors, Text 5 is a 124 -word text with 16 spelling errors, and Text 6 is a 225-word text with 48 spelling errors. The texts are included in Appendix B in the two versions of the text packet and also in Appendix $C$ with the spelling errors highlighted.

McColly (1970) reports that when texts are written in poor handwriting, they tend to receive lower scores for overall quality. He 
claims that the only solution to this problem is for essays to be typed. Since the physical appearance of a text, including the quality of the handwriting, is related to the overall rating the text is given (McColly), the six texts in this research project are presented in typewritten form.

\section{SCORING}

The scoring system employed in this study is the Test of Written English (TWE) six-point Scoring Guide, which is a standardized scoring system. It is well-accepted by ESL professionals and is considered a reliable and valid scale used in the rating of ESL students' written work. (A sample of the scoring sheet and the two packets of six terts are included as Appendix B.)

The TWE scoring guide gives the following definitions and explanations for the six levels of writing competence:

SCORES

6 Demonstrates clear competencies in writing on both the rhetorical and syntactic levels, though it may have occasional errors.

A paper in this category

--effectively addresses the writing task

--is well organized and well developed

--uses clearly appropriate details to support a thesis or illustrate ideas

--displays consistent facility in the use of language

--demonstrates syntactic variety and appropriate word choice

5 Demonstrates competence in writing on both the rhetorical and syntactic levels, though it will probably have occasional errors.

A paper in this category

--may address some parts of the task more effectively than others 
--is generally well organized and developed

--uses details to support a thesis or illustrate an idea

--displays facility in the use of language

--demonstrates some syntactic variety and range of vocabulary

4 Demonstrates minimal competence in writing on both the rhetorical and sytactic levels.

A paper in this category

--addresses the writing topic adequately but may slight parts of the task

--is adequately organized and developed

--uses some details to support a thesis or illustrate an idea

--demonstrates adequate but possibly inconsistent facility with syntax and usage

--may contain some errors that occasionally obscure meaning

3 Demonstrates some developing competence in writing, but it remains flawed on either the rhetorical or syntactic level, or both.

A paper in this category may reveal one or more of the following weaknesses:

--inadequate organization or development

--inappropriate or insufficient details to support or illustrate generalizations

--a noticeably inappropriate choice of words or word forms

--an accumulation of errors in sentence structure and/or usage

2 Suggests incompetence in writing.

A paper in this category is seriously flawed by one or more of the following weaknesses:

--serious disorganization or under development

--little or no detail, or irrelevant specifics

--serious and frequent errors in sentence structure or usage

--serious problems with focus

1 Demonstrates incompetence in writing.

A paper in this category

--may be incoherent

--may be undeveloped

--may contain severe and persistent writing errors

(Copyright 1990 by Educational Testing Service) 
Two different versions of the packet were alternately distributed to the evaluators. Each packet contains the same six authentic terts. One version contains a combination of terts including some with misspellings and some with no misspellings, and the other version contains the opposite combination of terts. Since there are two versions of the text packet, each questionnaire and tert packet is numbered to identify which version it is. Odd numbers indicate one version, and even numbers indicate the other version. Evaluators' names are not recorded, nor can these numbers be linked to evaluators.

Thirty-one of the sirty-one texts were put in the packet in reverse order to help minimize an ordering effect. The packets are numbered from 1 to 61 . The organization of the reading packets is presented in Table I. The odd-numbered packets include this combination of texts ("clean" means corrected for spelling errors, and "errors" means including spelling errors): Text 1 - clean, Text 2 clean, Text 3 - errors, Text 4 - clean, Text 5 - errors, and Text 6 clean. The even-numbered packets include the opposite combination of the same sir texts: Text 1 - errors, Text 2 - errors, Text 3 - clean, Text 4 - errors, Text 5 - clean, and Text 6 - errors. For packets 31 to 61 , the same combinations of terts were used, but the texts were renumbered and put in reverse order to avoid an ordering effect. For the packets numbered 31 to 61 , Text 6 was numbered as Text 1, Text 5 as Text 2, and so on, for both odd- and even-numbered packets. Before compiling the results, the numbers of the texts were then 
converted back to the original numbers, so that the numbers for texts 1 to 30 correctly correspond with the numbers for texts 31 to 61 .

\section{TABLE I}

\section{ORGANIZATION OF READING PACKETS}

ODD-NUMBERED PACKETS (Numbers 1 to 29)

Without spelling errors

With spelling errors

12

TEXT

$\begin{array}{llll}3 & 4 & 5\end{array}$

EVEN-NUMBERED PACKETS (Numbers 2 to 30 )

Without spelling errors

With spelling errors

12

TEXT

3

456

ODD-NUMBERED PACKETS (Numbers 31 to 61 )

Without spelling errors

With spelling errors

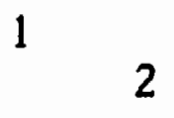

TEXT

356
$4 \quad 56$

EVEN-NUMBERED PACKETS (Numbers 32 to 60)

Without spelling errors

With spelling errors

TEXT

$\begin{array}{lllll}2 & 3 & 4 & & \end{array}$

Note: The texts in Packet Numbers 31 to 61 are in reverse order of Numbers 1 to 30 to account for an ordering effect. The texts in Packets 31 to 61 are converted back to the original tert numbers in the results. 


\section{STATISTICAL PROCEDURE}

The Mann-Whitney $U$ test, a non-parametric version of the $t$ test, was used to analyze the data. This test was chosen since it can be used with ordinal data and does not assume equal variances or a normal distribution in each of the two samples. The Mann-Whitney $U$ test was used to test the null hypothesis that the two samples have identical means. This test is based on the assumption that the sample scores are independent and the distributions are similar except for central tendency (Brown, 1988). 


\section{CHAPTER IV}

\section{RESULTS}

\section{ANALYSIS OF THE SPELLING ERROR DATA}

For the analysis of the spelling error data, each example was analyzed according to error type: deletion, insertion, metathesis, or substitution. Some samples showed the use of more than one error type.

After the analysis of the spelling error data was completed, the results were compiled in order to look for spelling error patterns. In the data consisting of 311 spelling errors, the most common mistake was the use of substitution (176 instances). Deletion was seen in the data 147 times. Insertion was used in the spelling error data 97 times. Finally, metathesis (transposition) was the least common source of error noted in these examples ( 34 cases). Major spelling error patterns are listed in Table II.

Some patterns emerge from this collection of data. Of course, a more extensive collection and analysis need to be done, but the patterns found in this small sample of errors offer interesting insights.

Regarding the use of substitution in the spelling error data, the letter " $e$ " was substituted for other letters 41 times, more often than any other letter. This suggests that these students may have difficulty 
TABLE II

MAJOR SPELLING ERROR PATTERNS

$\begin{array}{lcc}\text { Substitution } & & 176 \text { total } \\ \text { e for i } & 26 \\ \text { e for a } & 15 \\ \text { a for o } & 15 \\ \text { a for e } & 14 \\ \text { i for e } & 10 \\ \text { i for a } & 5 \\ \text { a for } \mathrm{i} & 5 \\ \text { s for c } & 5 \\ \text { Deletion } & 146 \text { total } \\ \text { e } & 64 \\ \text { (final e } & 25 \text { ) } & 14 \\ \text { i } & 7 \\ \text { o } & 6 \\ \text { a } & 6 \\ \text { u } & 6 \\ \text { l } & 6 \\ \text { n } & 5 \\ \text { h } & 5 \\ \text { p } & 4 \\ \text { f } & 4 \\ \text { word boundary } & 4 \\ \text { Insertion } & 97 \text { total } \\ \text { e } & 26 \\ \text { (final e } & 8 \text { ) } & 16 \\ \text { a } & 6 \text { ) } & 9 \\ \text { (initial a } & 8 \\ \text { word boundary } & 9 \\ \text { i } & 6 \\ \text { u } & 34 \text { total } \\ \text { Metathesis } & 4 \\ \text { l / e } & \end{array}$

Note: This table includes patterns where 4 or more examples were found in the spelling error corpus. 
distinguishing between vowel sounds in English, especially differentiating between sounds represented by the letters "e," "a," and "i." The letter " $e$ " was substituted for "i" 26 times, and for " $a$ " 15 times. It is interesting to note that the letter "e" does not exist in the Arabic language, but the letters " $a$ " and " $i$ " do. The incorrect use of the letter "e" for " $a$ " and " $\mathrm{i}$ " may suggest the use of overgeneralization.

Similarly, the letter " $a$ " was substituted for other letters 38 times. The letter " $a$ " was incorrectly used for the letter " 0 " 15 times, and for the letter "e" 14 times. It was also used for "i" 5 times. Again, this information suggests that these students have difficulty differentiating between vowel sounds in English. An interesting observation is that " $e$ " was substituted for " $a$ " 15 times, and "a" was substituted for "e" 14 times. These two vowel sounds appear to cause confusion for these students.

The letter " $\mathrm{i}$ " was substituted for other vowels 15 times. The letter " $\mathrm{i}$ " was incorrectly used for " $\mathrm{e}$ " 10 times, and " $\mathrm{i}$ " for " $\mathrm{a}$ " 5 times.

The vowel graphemes "o" and " $u$ " were substituted less often than those for other vowels. The letter " $u$ " was only incorrectly used 8 times, and the letter "o" was substituted only 6 times.

Regarding consonants, only a few noteworthy patterns were observed. The letter "s" was used for "c" 5 times, and " $k$ " for " $g$ " 3 times. One pattern that would be expected in the data is the used of " $b$ " for "p" since the letter "p" does not occur in Arabic. However, surprisingly there were only two examples of the substitution of "b" for " $p$," and, in fact, two examples of hypercorrection where " $p$ " is 
substituted for "b." There were some examples of substitution that occurred only once, but did not seem to demonstrate error patterns.

Errors resulting from deletion were observed in the data 147 times. Of these 147 examples, 97 of them are deletion of vowels. The most prominent pattern in these data is the deletion of the letter "e." The deletion of " $\mathrm{e}$ " is the cause of error 64 times. Of these 64 times, 25 of these are the deletion of final "e." One possible explanation of this error pattern is that the final " $e$ " in these examples is not pronounced, and unpronounced letters in Arabic do not exist. Arabic is a phonemic language with a one-to-one letter-to-sound correspondence, and every letter is pronounced. Perhaps these students delete the silent " $\mathrm{e}$ " because it is not pronounced. Furthermore, many of the other incidents of letter "e" deletion occur when the " $\mathrm{e}$ " is unpronounced. A possible explanation for the high number of "e" deletion in these data is that the letter is unpronounced, and, therefore, these students forget to write it.

Other vowel graphemes are deleted in the data, but not nearly as often as the vowel grapheme "e." Deletion of " $i$ " is the cause of error 14 times. The letter " 0 " is deleted 7 times, and " $u$ " and "a" 6 times each.

The deletion of vowels is clearly a cause of errors in these data, with 97 incidents in 311 words. However, the deletion of consonants was not as common. Consonants were deleted only 44 times. The letters "l" and " $n$ " were each deleted 6 times, and " $h$ " and " $p$ " were each deleted 5 times. The letter " $p$ " was deleted 4 times. The deletion of a word boundary was the source of error in 4 examples. (For 
example, the use of "incoclusion" instead of "in conclusion," includes deletion of a word boundary, as well as deletion of the letter " $n$ " between " 0 " and "c.") Other consonants were deleted 4 times or less in these data.

Insertion was the cause of error 97 times in these 311 words. Of these 97 insertions, 59 were vowels. The most commonly inserted letter was "e." The letter "e" was inserted 26 times, and in 8 of these cases, a final "e" was incorrectly added. This is an interesting contrast to the clear pattern of the deletion of final " $e$ " as discussed above. In 25 examples, a final " $e$ " is deleted where one is needed, and in 8 examples, a final " $e$ " is added where one is not necessary. This information suggests that these students are confused about final " $e$ " spelling.

The letter " $a$ " is inserted 16 times in these spelling errors. Of these 16 cases, 6 of these are the insertion of an initial "a." The letter "i" is inserted 8 times, the letter " $u$ " 6 times, and the letter " 0 " 3 times.

Word boundaries are incorrectly inserted in 9 of these data. (For example, the use of "some thing" for the word "something" includes an insertion of a word boundary since this single word is written as two words.) A final " $s$ " indicating a plural is inserted in 5 of these spelling errors. (It is possible that this type of error could be a grammatical mistake, but these five examples were counted as spelling mistakes in this study.) Other consonants are rarely inserted. Consonants are unnecessarily doubled in 7 examples. Also, the letter " $l$ " is incorrectly inserted 5 times.

Metathesis was the error type occurring the least often. There 
were only 34 examples of metathesis in this corpus. The letters "l" and " $e$ " were transposed 4 times, 3 of these in the final position and 1 in the medial position. These three pairs were each transposed twice in these data: "u"/"n," "r"/"o," and "o"/"p."

A phonological analysis of vowel grapheme substitution errors was done on the first 57 examples included in the first 117 words in the spelling error corpus in order to discover phonological patterns in the spelling error data. This analysis revealed that an incorrect vowel grapheme was used for the schwa sound in 18 of the 57 examples, or in $32 x$ of the cases. The letter "e" was incorrectly used for the schwa sound in 10 examples, and the letter " $a$ " was incorrectly used 6 times. The letters " $i$ " and " $u$ " were each used once. These findings indicate that these students have great difficulty knowing the value of a vowel when it is unstressed, that is, when is occurs as a schwa sound, and they incorrectly substitute other vowel graphemes where schwa sounds occur. A more thorough phonological analysis of spelling errors is needed, but this preliminary analysis offers interesting findings.

Based on the patterns that emerged in the analysis of this spelling error corpus, it seems that these Arabic-speaking students had the most difficulty with the letter "e." The letter "e" was involved in spelling errors in at least 154 cases (substitution 65 times, deletion 63 times, and insertion 26 times). The deletion of the letter " $e$ " was the most dominant error pattern in this corpus (63 instances), and the incorrect use of "e" for other vowels ("a" and " $\mathrm{i}$ ") was the next most 
dominant pattern (41 times). A more extensive collection and analysis of spelling errors is needed in order to establish more well-supported spelling error patterns.

\section{ANALYSIS OF THE RATERS SCORES \\ FOR THE SIX TEXTS}

Statistically significant differences were found between the scores for the version of the text that was clean and the version with spelling errors for three of the six texts. The results of the MannWhitney U Test comparing the texts with spelling errors and the texts without spelling errors are shown in Table III.

\section{TABLE III}

MANN-WHITNEY U TEST RESULTS COMPARING

TEXTS WITH SPELLING ERRORS AND

TEXTS WITHOUT SPELLING ERRORS

MEANS

TEXTS

$\begin{array}{llllll}1 & 2 & 3 & 4 & 5 & 6\end{array}$

$\begin{array}{lllllll}\text { CLEAN } & 3.19 & 2.76 & 1.48 & 3.48 & 2.83 & 3.24 \\ \text { SPFLLING ERRORS } & 3.09 & 1.83 & 1.19 & 3.39 & 2.57 & 2.78 \\ \text { DIFFERENCE } & 0.10 & 0.93 & 0.29 & 0.09 & 0.26 & 0.46\end{array}$

SPELLING ERROR

DENSITY

$\begin{array}{llllll}7 * & 25 * & 26 * & 9 x & 13 x & 21 x\end{array}$

$\begin{array}{lllllll}\text { MANN-WHITNEY U } & 243.5 & 362.5 & 308.5 & 251 & 275.5 & 318.5\end{array}$

P VALUE

$\begin{array}{llllll}.9592 & .0026 & .0482 & .811 & .3862 & .0298\end{array}$ 
A statistically significant difference was found between the score for a text with no spelling errors and the score for the same text with spelling errors for Texts 2, 3, and 6. A p value of less than .05 was chosen to determine statistical significance in this project. (This allows for the possibility that in one case out of twenty. the difference between the scores for the two texts was not a result of the presence of spelling errors, but perhaps because of another reason.)

A clearly significant difference was found between the scores for the two versions of the text for Texts 2, 3. and 6. However, a significant difference between the scores did not exist for Terts 1, 4, and 5, and even a much larger sample probably would not have produced significant differences for these three texts.

For Text 1, there was no difference between raters' scores for the clean texts and their scores for those with spelling errors (MannWhitney $U=243.5, p>.05$ ). A significant difference was found between the two sets of scores for Text 2 (Mann-Whitney $U=362.5$, p (.05) and for Text 3 (Mann-Whitney $U=308.5$. $p<.05$ ). The scores for Text 4 showed no significant difference (Mann-Whitney $U=251$, p >.05), nor did the scores for Text 5 (Mann-Whitney $U=275.5, p>.05$ ). Finally, the two sets of scores for Text 6 showed a significant difference (Mann-Whitney $U=318.5, p<.05)$.

\section{SPELLING ERROR DENSITY}

The data show a relationship between the $p$ values and statistical significance of a text and its spelling error density. The 
spelling error density of the texts is listed in Table IV.

\author{
TABLE IV \\ SPELLING ERROR DENSITY \\ OF THE TEXTS
}

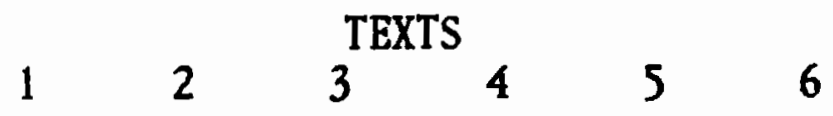

NUMBER OF SPELLING

ERRORS

12

32

26

14

16

48

NUMBER OF WORDS

176

126

101

160

124

225

SPELLING ERROR

DENSITY

$7 \% \quad 25 \% \quad 26 * \quad 9 \% \quad 13 * \quad 21 \%$

A statistical difference is seen between the two scores for Terts 2,3 , and 6 . It is interesting to note that these are the three terts with the highest spelling error density: Text 2 has a $25 \%$ spelling error density ( 32 spelling errors in a 126-word text), Text 3 has a $26 \%$ spelling error density ( 26 spelling errors in a 101-word text), and Text 6 has a $21 \%$ spelling error density (48 spelling errors in a 225 -word text). Terts 1,4 , and 5 do not show a significant difference between the two scores, and, in fact, they have the lowest spelling error density of the texts: Text 1 has a $7 \times$ spelling error density ( 12 spelling errors in a 176-word text), Text 4 has a $9 x$ spelling error density ( 14 spelling errors in a 160-word text), and Text 5 has a $13 \%$ spelling error density (16 spelling errors in a 124-word text). These figures suggest that there may be a relationship between spelling error density and the 
score a text receives. There was no significant difference between the scores for a text with no spelling errors and the same text with a low spelling error density (between 7 and 13x), as the data for Texts 1, 2, and 5 show. However, a significant difference does exist between the scores for a tert with no spelling errors and the same text with a high spelling error density (between 21 and $26 x$ ), as the data for Texts 3 , 4 , and 6 indicate.

The results suggest that a high density of spelling errors in a text (21 to $26 \%$ spelling error density) has a negative influence on readers' evaluation of it. However, a low density of spelling errors in a text (7 to $13 \%$ error density) does not show a significant negative influence. There is a significant difference between the mean scores a reader assigns to a text with a high density of spelling errors compared with the same text with no spelling errors. In this study, the scores are significantly lower for texts that include a high density of spelling errors compared with the same texts with no spelling errors. The scores are not significantly lower for texts with a low spelling error density compared with the same texts with no spelling errors. 


\section{CHAPTER V}

\section{SUMMARY AND DISCUSSION}

This research project is a two-part study investigating English spelling errors of students whose native language is Arabic. In Part One, spelling error data (see Appendix A) taken from writing samples of Arabic-speaking students enrolled in three ESL Programs in Oregon are collected and analyzed. These were existing writing samples that were kept on file, provided by the program directors at each school. The results of this analysis demonstrate dominant spelling error patterns used by these students.

Part Two of this study explores the effect of the presence of spelling errors in a written tert on readers' evaluation of the tert. A questionnaire was used (see Appendir B). Each subject received a packet of sir terts to evaluate. These terts were taken from the writing samples obtained for the spelling error data, as described above, and complete anonymity is guaranteed to the writers. There are two versions of the text packet, each with the same six terts, but with a different combination of texts free of spelling errors and texts with spelling errors. The evaluators scored each text using the Test of Written English (TWE) sir-point Scoring Guide (see Appendix B). The evaluators' scores were then analyzed to determine if the scores for the written passages that included spelling errors were significantly 
lower than the scores for the written passages that were free of spelling errors.

\section{DISCUSSION OF HYPOTHESES}

The results of this research contribute important information to the field of Teaching English to Speakers of Other Languages. Part One provides valuable, concrete information about the spelling errors of Arabic-speaking students, offers possible teaching suggestions, and suggests directions for further study in this area. Part Two presents research that supports the hypothesis that the presence of spelling errors in a written text has a significant negative effect on readers' evaluation of it when it has a high error density.

The hypotheses explored in this research project are supported by the results of this study:

1. Arabic-speaking students make a variety of spelling errors in English.

These errors are discussed in Part One, which is a descriptive study of spelling errors. The actual collection of spelling errors is included as Appendix A. This study provides concrete, empirical evidence of the exact spelling errors that Arabic-speaking students make, and actual spelling error patterns are determined from the corpus.

2. There are patterns to the English spelling problems of Arabic-speaking students. 
This hypothesis is supported based on the analysis of spelling error data in Part One, which is a descriptive study. Many spelling error patterns are found in the analysis of the data.

3. (A) Spelling errors in a written Engllsh text have a significant negative influence on readers' evaluation of it.

(B) There is a significant difference between the mean scores a reader assigns to a text with spelling errors compared with the same tert with no spelling errors. The scores will be significantly lower for a tert that includes various spelling errors, compared with the same text with no spelling errors.

These two hypotheses are supported based on the results of the research project done in Part Two. There is a negative relationship between the presence of spelling errors in a text and readers' evaluation of it when the text contains a high spelling error density, specifically between 21 to $26 \%$ error density. However, a low spelling error density in a text $(7$ to 13\% error density) does not show a negative relationship, according to this study. Scores are significantly lower for terts with a high spelling error density compared with the same texts with no spelling errors, but scores are not significantly lower when the terts have a low spelling error density. 


\section{DISCUSSION OF RESULTS}

This two-part study contributes valuable empirical information regarding the spelling problems of Arabic-speaking learners of English. Part One of this research project provides empirical evidence of the exact English spelling errors that Arabic-speaking students make. The actual corpus is included in this thesis as Appendix A. These data were classified according to error type using these four categories: deletion, insertion (epenthesis), metathesis (transposition), and substitution. These findings were then analyzed, and specific spelling error patterns were discovered. A dominant problem that is seen in these results is difficulty differentiating between vowels in English, especially "e," "a," and "i." The letter "e" is particularly problematic and is involved in the majority of spelling errors in these data. An initial phonological analysis indicates that the schwa sound is especially problematic and that incorrect vowel graphemes are used where schwa sounds occur. Incorrect vowel graphemes are substituted for the schwa sound 18 times in the 57 examples that were analyzed.

The most dominant spelling error patterns observed in this corpus are the following: " $e$ " is substituted for other vowel graphemes 65 times, " $\mathrm{e}$ " is deleted 64 times, "a" is substituted for other vowel graphemes 38 times, and " $\mathrm{e}$ " is inserted 26 times.

More specifically, regarding the substitution of the letter e for other vowel graphemes, "e" is incorrectly used for "i" 26 times, and "e" for "a" 15 times. Of the 64 cases of the deletion of "e," 25 of these 
examples are deletion of final "e." The letter " $a$ " is substituted for other vowel graphemes 38 times. In 15 examples, "a" is substituted for " 0 ," and in 14 cases, " $a$ " is incorrectly used for "e." Finally, " $e$ " is incorrectly inserted 26 times, and 8 of these involve the insertion of final "e."

The results of Part Two of this study show a relationship between the $p$ values and statistical significance of a text and its spelling error density. A statistical difference is seen between the two scores for the three texts with the highest spelling error density, between 21 to $26 \%$. However, the three terts with the lowest spelling error density, 7 to $13 \%$ error density, do not show a significant difference between the two scores. These figures suggest that there is a relationship between spelling error density and the score a text receives for its overall quality.

The results indicate that a high density of spelling errors in a text (21 to $26 \%$ spelling error density) has a negative influence on readers evaluation of it. However, a low density of spelling errors in a text ( 7 to $13 \%$ error density) does not show a significant negative influence. There is a significant relationship between the density of spelling errors in a text and the scores that evaluators assign to the text. In this study, the scores are significantly lower for texts that include a high density of spelling errors compared with the same texts with no spelling errors. The scores are not significantly lower for texts with a low error density compared with the same texts with no spelling errors. 


\section{THE IMPORTANCE OF THIS RESEARCH PROJECT}

The English spelling problems of ESL students is an area lacking in research. The particular spelling problems of Arabic-speaking students is an especially important concern, and yet little investigation has been done regarding this subject.

Part One of this research project is an in-depth investigation of these spelling problems. This empirical study offers valuable information for teachers who would like to help Arab students with their spelling problems. The results of this study suggest important directions for remedial spelling practice. Clearly, Arab students need to improve their ability to differentiate between English vowels in writing, with special focus on the letter "e." A preliminary phonological analysis indicates that the schwa sound is especially problematic.

The results of Part Two of this project are not only relevant for Arab students, but offer valuable empirical information regarding the influence of spelling errors in a text on the score that it receives. This study suggests that a high spelling error density in a tert ( 21 to $26 x$ ) has a significant negative influence on readers' evaluations of that text. However, a low spelling error density ( 7 to $13 x$ ) does not have a significant negative influence on readers' scores. These findings indicate that the presence of some spelling errors does not cause an evaluator to give a text a lower score for overall writing quality. However, the presence of many spelling errors in a tert does cause an evaluator to give a tert a lower score for overall writing quality. 
Many linguists and educators make the assumption that spelling errors in a written text negatively affect the grade that it receives. However, prior to the present research, no study was found to specifically investigate this assumption and to support it with empirical evidence. This research project addresses this Important issue and offers concrete, empirical information that is a valuable contribution to the field of TESOL. Teaching English to Speakers of Other Languages, and to other fields, as well.

\section{TEACHING SUGGESTIONS}

As Part Two of this study suggests, the presence of a high density of spelling errors in a text can have a significant negative influence on the evaluation of it. Therefore. students with serious spelling problems need intensive remedial spelling practice.

Students are usually at a loss for ways that they can improve their spelling skills, and ESL teachers seem to have little knowledge about what to do to help these students. It seems that spelling is rarely addressed in ESL programs. As Ibrahim (1978) observes, "the foreign learner . . . is rarely exposed to a systematic treatment of spelling rules. Instead, he is left to infer these rules by himself" ( $p$. 211). Even if a student does learn spelling rules, if they are learned without their exceptions, then the learning is not sufficient, and spelling errors will still occur. Indeed, students need to be presented with a comprehensive coverage of the English spelling system.

Wolfram and Johnson (1982) believe that it is important "for 
educators to concentrate on understanding the extensive patterning that does exist in the current [English spellingl system and the various subsystems that have been incorporated into it" (p. 207). Based on this suggestion, it seems that teachers need to familiarize themselves with the patterns of sound-symbol correspondence that exist in the English language, then explicitly teach them to students who need to improve their spelling ability, especially Arab students. An annotated bibliography of books that include descriptions of these sound-symbol correspondences is included as Appendix E. These books are helpful resources for the teaching of spelling. However, it is clear that there is a strong need for spelling books designed for ESL students and specifically for Arabic-speaking students.

One possible teaching approach might be for students to learn about spelling patterns in the classroom, then do specially designed spelling practice as homework, similar to Ball's (1986) recommendation for handwriting practice for Arab students. Ball suggests that these exercises are done outside of class and are regularly monitored by the instructor. (Actually, the handwriting of Arab students probably influences the rating of their written work, and that is an area for further study.)

Other practices that might be especially helpful for Arab students who want to improve their spelling could include participation in specially-designed spelling workshops, personalized homework assignments, and recommended independent spelling practice. Development of these kinds of activities in ESL programs 
could help these students improve their spelling ability.

Based on the results of the present study. it is clear that Arabicspeaking students need special spelling practice involving English vowels. Thompson-Panos and Thomas-Ruzic (1983) suggest that these students recelve a systematic presentation of the spoken vowel variations and their common representations in writing, as well as the relationship of spelling to word families, roots, and derivations. Schane (1970) agrees with this approach and adds that rules for deriving alternative pronunciation from the same spelling patterns need to be presented, as well.

Part One of this research project provides empirical evidence to support many of the observations made by Thompson-Panos and Thomas-Ruzic (1983) from their experience in the ESL classroom. They report that Arabic speakers are often inconsistent in their representation of vowels in English, and that "the systems for representation of vowels in the two languages lack close correspondence" (p. 612). The findings of the spelling error analysis in this study clearly support their claims.

Furthermore, Thompson-Panos and Thomas-Ruzic refer to the fact that much of the Arabic language is spelled without vowels, and they observe that Arab students often delete vowels in written English. Joy (1985) notes that Arab students must pay special attention to vowel insertion in English. In fact, the present study reveals 97 cases of vowel grapheme deletion in the 311-word spelling error corpus, supporting their claims. In addition, vowel graphemes were incorrectly inserted in 59 cases. Thompson-Panos and Thomas- 
Ruzic point out that the English vowel system is complex and distiguishes between eleven or more distinctive vowel phones, but uses only six vowel graphs (including " $y$ ") in writing. They explain that "the meaningful vowel variations found, for example, in beat, bit, bait, bet, pot, bat, bought, boat, put , but , boot, and bout can be difficult for the Arab to discriminate in listening, speaking, and reading, as well as in writing" (p. 612). This argument is clearly supported by the findings of this study since the spelling error data show distinct patterns which suggest confusion about vowels and inability to differentiate between them. A preliminary phonological analysis of vowel grapheme substitution errors indicates that the schwa sound is particularly problematic. Students appear to have difficulty knowing the value of a vowel when it is unstressed, and special practice focusing on the spellings of the schwa sound would be helpful.

\section{IN CONCLUSION}

The information presented in this thesis offers valuable insights that can increase teachers' awareness of the spelling problems of Arabic-speaking students and encourage understanding of these difficulties. Furthermore, this thesis provides empirical evidence that shows the negative influence that a high density of spelling errors can have on readers' evaluation of a written text. In addition, this thesis offers suggestions for helping students improve their spelling ability. 
It is hoped that spelling practice will be incorporated into TESOL curricula, according to students' needs.

\section{DIRECTIONS FOR FURTHER STUDY}

One possibility for further research is to replicate one or both of the two studies that are presented in this thesis. Replication of these studies can provide additional empirical evidence, and it can be determined whether future findings support the results of the present research.

An in-depth phonological analysis of Arabic-speaking students' spelling errors is needed in order to discover phonological patterns. An extensive analysis of sound-symbol correspondences that occur in spelling errors would provide valuable information.

As mentioned previously, another important subject worth investigating is the handwriting problems of Arab students. One possibility for research could be a study based on the design of Part Two of the present project. Ball's (1986) article "Writing English Script: An Overlooked Skill" provides an interesting discussion of the handwriting problems of Arab students.

Regarding teaching methodology, research will need to be done to investigate the effectiveness of different approaches used to help students improve their spelling. Empirical evidence can suggest the most effective methods.

Spelling books for native speakers are available, but spelling books designed specifically for non-native speakers are needed. A 
book is needed, for ESL students and teachers alike, that includes a presentation of the spoken vowel variations in English and their representations in writing. It would be extremely helpful for students and teachers to have one good reference book for English spelling practice. Resources for the improvement of English spelling need to be created for ESL students and teachers, and especially for Arabicspeaking students A spelling book specifically designed for Arab students would be welcome and could be used for independent study or classroom practice. It is hoped that more resources for improving English spelling will soon be available for Arabic-speaking students. 


\section{REFERENCES}

Ball, W. S. (1986). Writing English script: An overlooked skill. English Language Teaching Journal. 40(4), 291-298.

Beck. R. D. (1979). An error analysis of free composition. Teachers of English: Arabian monthly. 30 20-26.

Birckbichler, D. W. (1977). Communication and beyond. In J. K. Phillips (Ed.), The language connection: From the classroom to the world (pp. 53-94). Skokie, IL: National Textbook.

Brown, J. D. (1988). Understanding research in second language learning: A teacher's guide to statistics and research design. New York: Cambridge University Press.

Burt, M. K., \& Kiparsky, C. (1972). The Gooficon: A repair manual for English. Rowley. MA: Newbury House.

Charney, D. (1984). The validity of using holistic scoring to evaluate writing: A critical overview. Research in the teaching of English. $18(1), 65-81$.

Corder, S. P. (1975). The language of second-language learners: The broader issues. Modern Language Journal. 59, 409-413.

Farquharson, M. (1988). Ideas for teaching Arab students in a multicultural setting. (ERIC Document Reproduction Service No. ED 296 575).

Freedman, S. (1979). How characteristics of student essays influence teachers' evaluations. Journal of Educational Psychology. 71 328-338.

Hanzeli, V. E. (1975). Learner's language: Implications of recent research for foreign language instruction. Modern Language Journal. 59, 426-432. 
Hendrickson, J. M. (1977). Error analysis and selective correction in the adult ESL classroom: An experiment. (ERIC Document Reproduction Service No. ED 135 259).

Hendrickson, J. M. (1987). Error correction in foreign language teaching: Recent theory, research, and practice. In M. Long and J. Richards (Eds.), Methodology in TESOL: A book of readings (pp. 355-369). New York: Newbury House.

Hildreth, G. (1955). Teaching spelling: A guide to basic principles and practices. New York: Henry Holt.

Hodges, R., \& Rudorf, E. H. (1966). Searching linguistics for cues to the teaching of spelling. In T. D. Horn (Ed.), Research on Handwriting and Spelling (pp. 29-35). Champaign, IL: National Council of Teachers of English.

Hutchinson, D. D. (1984). Some predictable errors of Arab students in written English. TEAM: Journal of the English Language Center. 48. $1-12$.

Ibrahim, M. (1978). Patterns in spelling errors. English Language Teaching Journal. 32(3), 207-212.

Johansson, S. (1973). The identification and evaluation of errors in foreign languages: A functional approach. In. J. Svartik (Ed.), Errata: Papers in error analysis (pp. 102-114). Lund, Sweden: CWK Gleerup.

Joy, C. B. (1985). Guidelines for prospective EFL teachers in Saudi Arabia. (ERIC Document Reproduction Service No. ED 267611 ).

Lehn, W., \& Slager, W. R. (1959). A contrastive study of Egyptian Arabic and American English: The segmental phonemes. Language Learning $9(1-2), 25-33$.

Lewis, S. D. (1984). Common problems in teaching writing, spelling and pronunciation to Arab students. TEAM: Journal of the English Language Center. 49, 22-25.

McColly, W. (1970). What does educational research say about the judging of writing ability? Journal of Educational Research. 64(4), 147-156. 
Nas, G. (1975). Determining the communicative value of written discourse produced by L2 learners. Utrecht. The Netherlands: Institute of Applied Linguistics.

Natusch, B. (1984). Correlations between spelling quizzes and students' examination results. TEAM: Journal of the English Language Center. 46 14-15.

Richards, J. C. (1973). Error analysis and second language strategies. In J.W. Oller, Jr. and J. C. Richards (Eds.), Focus on the learner: Pragmatic perspectives for the language teacher (pp. 114-135). Rowley, MA: Newbury House.

Schane, S. (1970). Linguistics, spelling, and pronunciation. TESOL Quarterly. 4(2), 137-141.

Sparks, J. S. (1988). Syntactic complexity, error and the holistic evaluation of ESL student essays. Unpublished thesis, Portland State University.

Sternglass, M. S. (1974). Close similarities in dialect features of black and white college students in remedial composition classes. TESOL Quarterly. 8. 271-283.

Tesdell, L. (1984). Spelling tips for teachers. TEAM: Journal of the English Language Center. $46,17$.

Thompson-Panos, K, \& Thomas-Ruzic, M. (1983). The least you should know about Arabic: Implications for the ESL writing instructor. TESOL Quarterly 17, 609-623.

Wolfram, W., \& Johnson, R. (1982). Phonological analysis: Focus on American English. Washington, DC: The Center for Applied Linguistics.

Yorkey, R. (1979). Practical EFL techniques for teaching Arabicspeaking students. In J. E. Alatis and R. Crymes (Eds.), The human factors in ESL (pp. 57-85). Washington, DC: TESOL. 
APPENDIX A

SPELLING ERROR DATA 


\begin{tabular}{|c|c|}
\hline Spelling Error & Correct Soelling \\
\hline becuaes & because \\
\hline $\begin{array}{l}\text { dengers } \\
\text { heumen }\end{array}$ & $\begin{array}{l}\text { dangerous } \\
\text { human }\end{array}$ \\
\hline aniemals & animals \\
\hline diestroy & destroy \\
\hline exampel & example \\
\hline contry & country \\
\hline liek & like \\
\hline diesert & desert \\
\hline lievs & lives \\
\hline ther & there \\
\hline mony & money \\
\hline electrsity & electricity \\
\hline waht & what \\
\hline thit & that \\
\hline then & than \\
\hline electrcity & electricity \\
\hline effect & affect \\
\hline reasorecas & resources \\
\hline countnue & continue \\
\hline energys & energies \\
\hline becuase & because \\
\hline hop & hope \\
\hline hilthy & healthy \\
\hline bisey & busy \\
\hline think & things \\
\hline sawet & saw it \\
\hline her & here \\
\hline farst & first \\
\hline think & thing \\
\hline evry badey & everybody \\
\hline thes & these \\
\hline ruilas & rules \\
\hline rulas & rules \\
\hline oll & all \\
\hline peopel & people \\
\hline theus & these \\
\hline streat & streets \\
\hline celaen & clean \\
\hline thear & there \\
\hline naeas & nice \\
\hline peapel & people \\
\hline beacuse & because \\
\hline theay & they \\
\hline
\end{tabular}




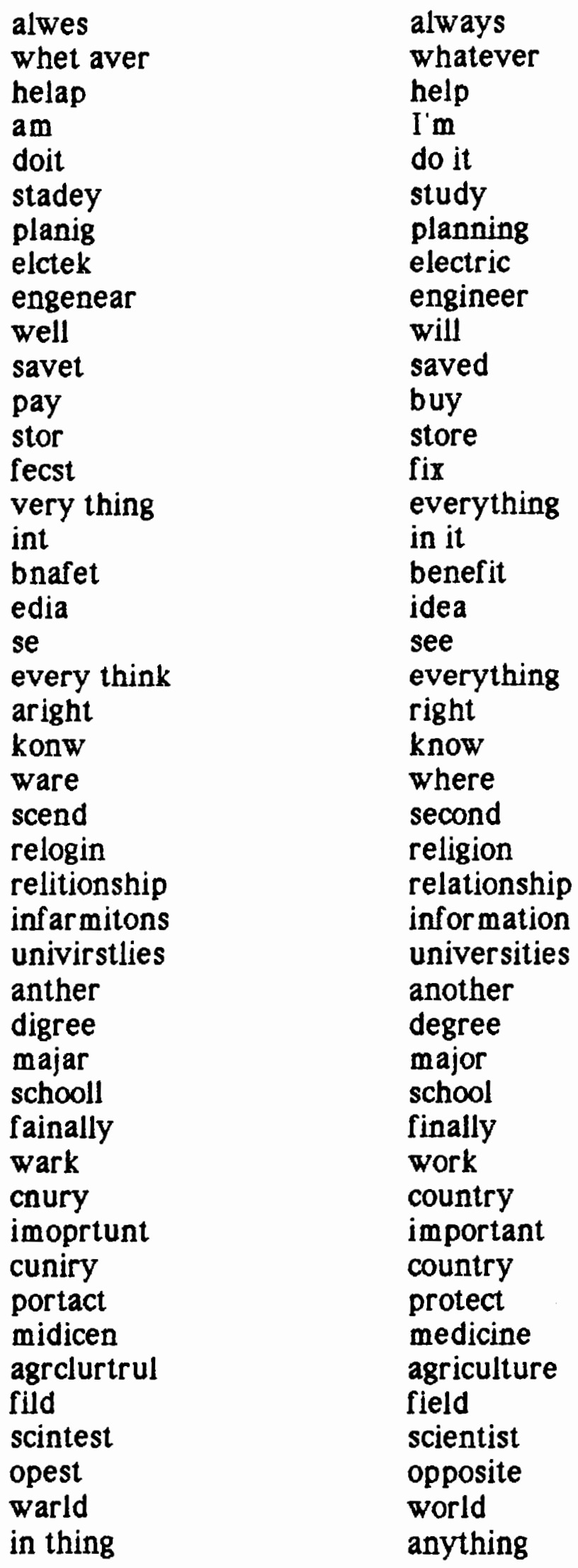


scintest's

carful

concluation

saf

protact

satsfid

importart

witch

enviroment

develope

elemant

resouces

pepole

wright

fowlloing

know

scande

andistral

factries

religen

asslam

thes

becouse

leav

basc

seastam

secaned

theired

bed

reson

peapole

dan't

countrey

speack

alwasy

uosed

afread

becaus

afouned

astuabed

riath

proplem

word

defiet

ather scientists

careful

conclusion

safe

protect

satisfied

important

which

environment

develop

element

resources

people

write

following

now

second

industrial

factories

religion

Islam

these

because

leave

basic

system

second

third

bad

reason

people

don't

country

speak

always

used

afraid

because

found

stupid

right

problem

world

fight

other 


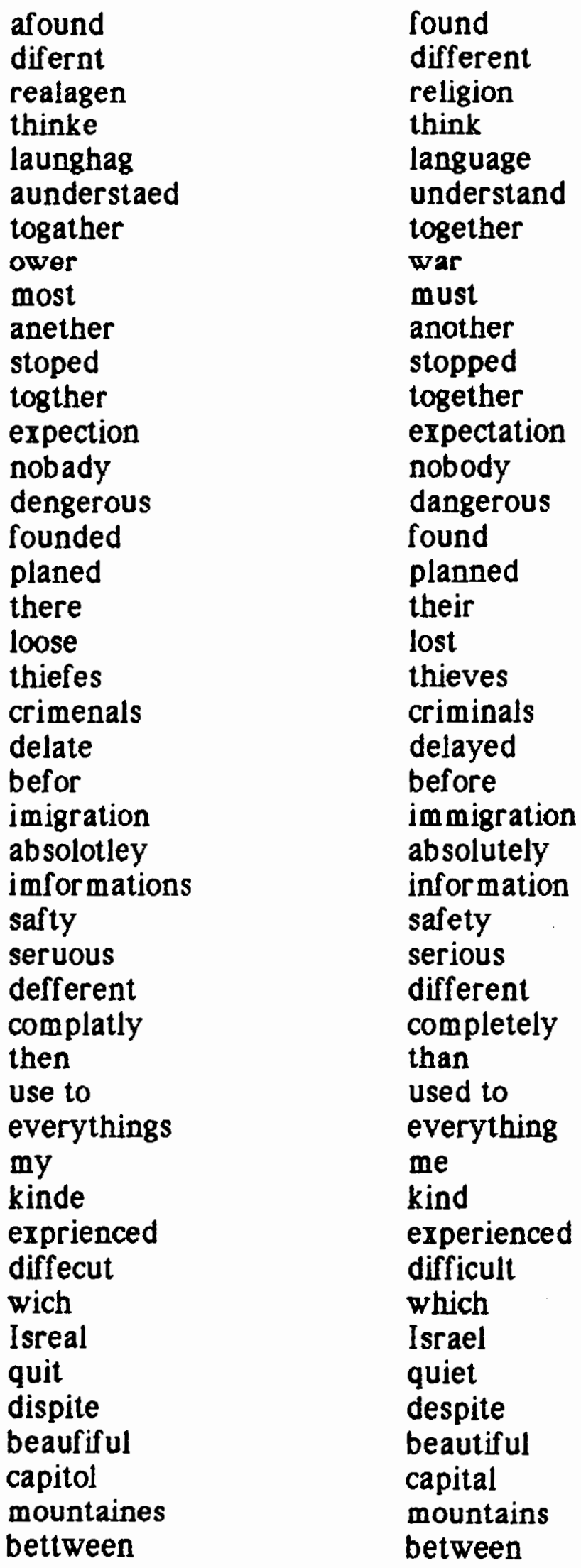




\begin{tabular}{|c|c|}
\hline $\begin{array}{l}\text { hapend } \\
\text { steel }\end{array}$ & $\begin{array}{l}\text { happened } \\
\text { steal }\end{array}$ \\
\hline $\begin{array}{l}\text { rap } \\
\text { braking }\end{array}$ & rape \\
\hline $\begin{array}{l}\text { evry thing } \\
\text { hapen } \\
\text { toke }\end{array}$ & $\begin{array}{l}\text { everything } \\
\text { happen } \\
\text { took }\end{array}$ \\
\hline emagen & imagine \\
\hline hull & whole \\
\hline theros & throws \\
\hline thos & those \\
\hline gaverment & government \\
\hline defrent & different \\
\hline volentyrs & volunteer \\
\hline sodurs & soldiers \\
\hline thausent & thousand \\
\hline thing & think \\
\hline evry & every \\
\hline citesenman & citizen \\
\hline volentyr & volunteer \\
\hline soldur & soldier \\
\hline atherwise & otherwise \\
\hline is & as \\
\hline scecand & second \\
\hline biger & bigger \\
\hline conutrys & countries \\
\hline by & buy \\
\hline bild & build \\
\hline factoryes & factories \\
\hline dangrous & dangerous \\
\hline avaliable & available \\
\hline particulary & particularly \\
\hline controling & controlling \\
\hline whille & while \\
\hline diffrences & differences \\
\hline worng & wrong \\
\hline diffecult & difficult \\
\hline adition & addition \\
\hline diffucat & difficult \\
\hline weating & waiting \\
\hline incoclusion & in conclusion \\
\hline intersting & interesting \\
\hline adieas & ideas \\
\hline diffucalty & difficulty \\
\hline happenen & happened \\
\hline
\end{tabular}




\begin{tabular}{|c|c|}
\hline Amirecan & American \\
\hline A mirecans & Americans \\
\hline noiesy & noisy \\
\hline famillier & familiar \\
\hline suriprisd & surprised \\
\hline $\begin{array}{l}\text { countinued } \\
\text { diffcult }\end{array}$ & $\begin{array}{l}\text { continued } \\
\text { difficult }\end{array}$ \\
\hline knoleged & knowledge \\
\hline diffeculty & difficulty \\
\hline pronouns & pronounce \\
\hline explaination & explanation \\
\hline independed & independent \\
\hline statment & statement \\
\hline $\begin{array}{l}\text { broud } \\
\text { does'not }\end{array}$ & $\begin{array}{l}\text { proud } \\
\text { does not }\end{array}$ \\
\hline any thing & anything \\
\hline happend & happened \\
\hline Kwait & Kuwait \\
\hline thet & that \\
\hline th & the \\
\hline pnisedert & president \\
\hline thretening & threatening \\
\hline one & on \\
\hline some thing & something \\
\hline barbarich & barbaric \\
\hline iraqy & Iraqi \\
\hline amircan & American \\
\hline ase & as \\
\hline concenes & concerns \\
\hline thire & their \\
\hline citezents & citizens \\
\hline praticpating & participating \\
\hline preparationes & preparations \\
\hline I m & I am \\
\hline ounest & honest \\
\hline thire & there \\
\hline towared & toward \\
\hline expectatons & expectations \\
\hline returne & return \\
\hline happene & happen \\
\hline completly & completely \\
\hline educted & educated \\
\hline modren & modern \\
\hline wondred & wondered \\
\hline managming & managing \\
\hline
\end{tabular}




thind
conivent
matrel
chiper
desinged
resived
wather
dirining
baisic
meteriers
laphing
desiding
magazin
opning
lauphing
sute case
carfully
befor
nepheu
congrageulation
difecult
caplin
hem
scince
varies
peopl
behaviour
experince
psycology
aproaches
psychologyist
peron
buseniss
pychologist
influencess
sessitons
discoveres
faill
influnces
failur
busness
Marrige

thing convenient material cheaper designed received weather during basic materials laughing deciding magazine opening laughing suitcase carefully before nephew congratulations difficult captain him science various people behavior experience psychology approaches psychologist person business psychologist influences sessions discovers fail influences failure business marriage 


\section{APPENDIX B}

SCORING SHEET, SCORING GUIDE, AND

TWO VERSIONS OF THE PACKET OF SIX TEXTS 
SCORING SHEET

Please give each text a score of $6,5,4,3,2$, or 1 using the scoring guide below:

$\underline{\text { SCORE }}$

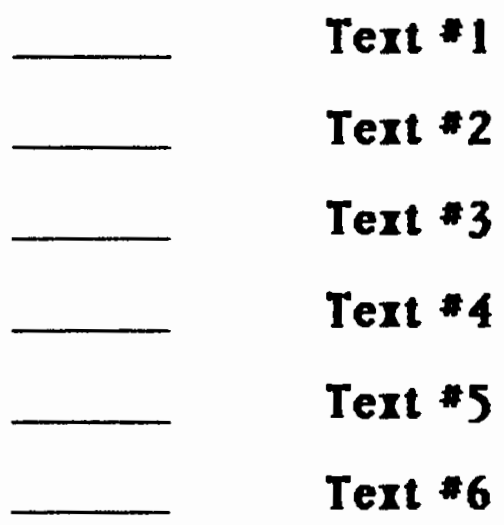

Thank you very much for your participation. 
TWE SCORING GUIDE *

\section{SCORES}

6 Demonstrates clear competencies in writing on both the rhetorical and syntactic levels, though it may have occasional errors.

A paper in this category

--effectively addresses the writing task

--is well organized and well developed

--uses clearly appropriate details to support a thesis or illustrate ideas

--displays consistent facility in the use of language

--demonstrates syntactic variety and appropriate word choice

5 Demonstrates competence in writing on both the rhetorical and syntactic levels, though it will probably have occasional errors.

A paper in this category

--may address some parts of the task more effectively than others

--is generally well organized and developed

--uses details to support a thesis or illustrate an idea

--displays facility in the use of language

--demonstrates some syntactic variety and range of vocabulary

4 Demonstrates minimal competence in writing on both the rhetorical and sytactic levels.

A paper in this category

--addresses the writing topic adequately but may slight parts of the task

--is adequately organized and developed

--uses some details to support a thesis or illustrate an idea

--demonstrates adequate but possibly inconsistent facility with syntax and usage

--may contain some errors that occasionally obscure meaning 
3 Demonstrates some developing competence in writing, but it remains flawed on either the rhetorical or syntactic level, or both.

A paper in this category may reveal one or more of the following weaknesses:

--inadequate organization or development

--inappropriate or insufficient details to support or illustrate generalizations

--a noticeably inappropriate choice of words or word forms

--an accumulation of errors in sentence structure and/or usage

2 Suggests incompetence in writing.

A paper in this category is seriously flawed by one or more of the following weaknesses:

--serious disorganization or underdevelopment

--little or no detail, or irrelevant specifics

--serious and frequent errors in sentence structure or usage

--serious problems with focus

1 Demonstrates incompetence in writing.

A paper in this category:

--may be incoherent

--may be undeveloped

--may contain severe and persistent writing errors

* Copyright 1990 by Educational Testing Service 


\section{Text *1}

Do you agree or disagree with the following statement? Use specific reasons and examples to support your position.

\section{"Money Doesn't Buy Happiness"}

(Money Doesn't buy happiness)

If anybody think that money can buy happiness I think he is wrong. There is nobody want to sell his happiness and we must consider these two condition in our mind that everybody in the world wants to live in a good life with no problems in it. There are many people who spend a lot of money just to be in happiness mood.

Firstly, most of the people divide their time between their work and their social life. They don't want to spend all their time in collecting money. They want to enjoy themselves in their life. They want to be happy with their families and their friends.

Secondly, most of the rich and wealthy people spend a lot of money just to be happy. You can see them spending their money to travel to other countries, making parties and going to movies. All these things just to make them happy.

In conclusion, I can't imagine that there is some people who give a chance to the money to buy their happiness. 


\section{Text $* 2$}

Some people like to travel by plane and others prefer to go by car. Which means of travel do you prefer and why?

Some people like to travel by plane but I prefer to travel by car because I can see the bird and the sea and the tree and we can stop and enjoy the good weather and I prefer the car because it take a long time in travel more than the plane because of that reason we can stop and play and if there's a sea we can swim but in the plane we have to sit in there we don't have to move. and when we travel by car we can stop the car and put ourfood and our drink and sit there until we want then we can complete our travel because all of these reason I like and prefer traveling by car. 


\section{Text *3}

\section{What three things would you like your American classmates to know and understand about your country? Why?}

I like in American the first seastam and the secaned free country and the theired study in her because in my country the seastam is very bed and the reson almost the peapole they dan't walk for any seastam because the leaders very bad and my countrey not free country and no any person he can speack or do any thing the reason is the leaders alwasy they uosed the ower and all the peapole they afread for this and in my country the learn is very bad becaus afouned astuabed teacher because alwasy this teacher they thinks they alwasy riath 


\section{Text $* 4$}

Living in another culture always carries the risk that one will be misunderstood, either because of different cultural customs or because of language problems.

Describe an incident that has happened to you since you came to the U.S. in which there was a misunderstanding. Describe what happened and what we can learn from this experience.

It is normal for anyone who lives in a different cultural customs or with people who speak a different language to have some difficulty in understand the $\mathrm{m}$. Therefore he might get in trouble because of his small experience.

I remember an incident which happened to me and made an impact for me. I had a party with some American friends. Since Americans like to have such a noisy parties that I didn't familiar with, I surprised for their behavior then. They were dancing, drinking, and kissing each other in a strange way. Then, the time came to have our dinner, I sat down to eat. After having the dinner, we sat to talk while the other continued their crazy dance. I was no longer bear that noise and preferred to escape.

In fact, it is difficult from a person to get along on a different cultural unless he or she study it to have enough knowledge. 


\section{$\underline{T e x t} * 5$}

What three things would you like your American classmates to know and understand about your country? Why?

I will wright her about first subject or I will answer the first question. The three things I would like my American classmates to know and understand about my country are in the fowlloing. First, I want tell my classmates about the farms which we have in Saudi Arabia. There are much farms in Saudi Arabia know. Scande thing I want tell my American classmates about my country is andistral we have much factries. The last thing I want tell my American classmates about my country is about the religen of my country. My country religen is asslam. I wan tell my class mates about thes three things becouse I want leav my class mates see the basc things we had in Saudi Arabia. 


\section{Text $\# 6$}

Every country in the world has its share of problems.

Discuss the two biggest problems your country has. What is your country trying to do about the problems? Do you think you will be able to help in any way? How will you help?

In fact the biggest problems in U.A.E at this time is the war that between us and Iraq, because Saddam Hussein started with Kuwait and we know what happened there from: steal, rape, breaking everything to kill, so that what happened to Kuwait then what will happen to U.A.E if he decided to take it as he took Kuwait, he did not said just take it he said 'I'll throw a chemical bombs on you' he means us, so imagine what will happen to the whole area if he throws those bombs.

From here we say it's the biggest problem in U.A.E that small and safe country.

The government made different points to face the problem, one of them is the volunteer soldiers, and more than 30 thousand men have been a volunteer soldiers between 15-40 years old. And I think every citizen in U.A.E must be a volunteer soldier otherwise U.A.E will be the same as Kuwait.

The second problem is bringing everything from the bigger countries, it's OK now for us because we have got the oil or the money which we buy with every single thing from them, and let's say the oil will stay for 50 more years so what we'll do after that. From this point we should think about another power like growing or build a factories 
SCORING SHEET

Please give each text a score of $6,5,4,3,2$, or 1 using the scoring guide below:

\section{SCORE}

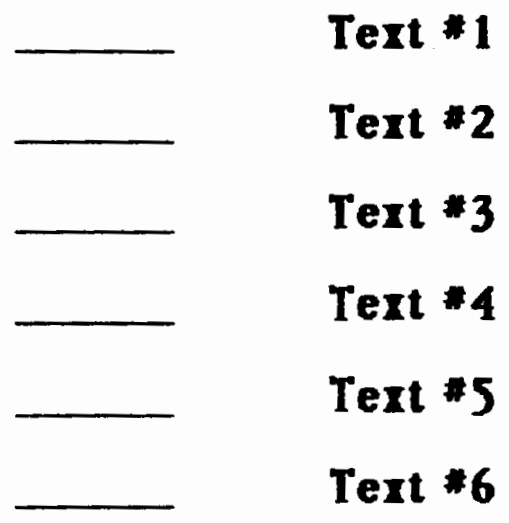

Thank you very much for your participation. 


\section{TWE SCORING GUIDE *}

\section{SCORES}

6 Demonstrates clear competencies in writing on both the rhetorical and syntactic levels, though it may have occasional errors.

A paper in this category

--effectively addresses the writing task

--is well organized and well developed

--uses clearly appropriate details to support a thesis or illustrate ideas

--displays consistent facility in the use of language

--demonstrates syntactic variety and appropriate word choice

5 Demonstrates competence in writing on both the rhetorical and syntactic levels, though it will probably have occasional errors.

A paper in this category

--may address some parts of the task more effectively than others

--is generally well organized and developed

--uses details to support a thesis or illustrate an idea

--displays facility in the use of language

--demonstrates some syntactic variety and range of vocabulary

4 Demonstrates minimal competence in writing on both the rhetorical and sytactic levels.

A paper in this category

--addresses the writing topic adequately but may slight parts of the task

--is adequately organized and developed

--uses some details to support a thesis or illustrate an idea

--demonstrates adequate but possibly inconsistent facility with syntax and usage

--may contain some errors that occasionally obscure meaning 
3 Demonstrates some developing competence in writing, but it remains flawed on either the rhetorical or syntactic level, or both.

A paper in this category may reveal one or more of the following weaknesses:

--inadequate organization or development

--inappropriate or insufficient details to support or illustrate generalizations

--a noticeably inappropriate choice of words or word forms

--an accumulation of errors in sentence structure and/or usage

2 Suggests incompetence in writing.

A paper in this category is seriously flawed by one or more of the following weaknesses:

--serious disorganization or underdevelopment

--little or no detail, or irrelevant specifics

--serious and frequent errors in sentence structure or usage

--serious problems with focus

1 Demonstrates incompetence in writing.

A paper in this category:

--may be incoherent

--may be undeveloped

--may contain severe and persistent writing errors

* Copyright 1990 by Educational Testing Service 


\section{Text *1}

\section{Do you agree or disagree with the following statement? Use specific reasons and examples to support your position.}

\section{"Money Doesn't Buy Happiness"}

(Money Desn't buy happiness)

If anybody think that money can buy happiness I think he is wrong. There is nobody want to sell his happiness and we must consieder these two condition in our mind that everybody in the world wants to live in a good life with no problems in it. There are many people who spend a lot of money just to be in happiness mood.

Firstly, most of the people divid their time between their work and their social life. They don't want to spend all their time in collecting money. They want to enjoy themselfes in their life. They want to be happy with their families and their friends.

Secondly, most of the rich and wealth people spend alot of money just to be happy. You can see them spending their mony to travell to ather countries, makeing parties and going to movies. All these things just to make them happy.

In conclusion, I can't imagen that there is some people who give a chance to the money to buy their happienss. 


\section{$\underline{\operatorname{Text} * 2}$}

Some people like to travel by plane and others prefer to $g 0$ by car. Which means of travel do you prefer and why?

Some people like to travel by plane but I prefer to travel by car becaws I can see the baerd and the see and the tree and we can stop and enjoy the good wiethar and I prefer the car becaws it take a long taim in travel maor than the plane becaws of that rezaun we can stoop and play and if thers a see we can sweem but in the plane we have to seet in thaer we dont have to move. and when we travel by car we can stoop the car and boot awar food and awar drenk and seat ther antel we want then we can kowmblet aur travel becaws oll of thes rezawn I laik and prefer travling by car. 


\section{Text $: 3$}

What three things would you like your American classmates to know and understand about your country? Why?

I like in America the first system and the second free country and the third study in here because in my country the system is very bad and the reason almost the people they don't work for any system because the leaders very bad and my country not free country and no any person he can speak or do anything the reason is the leaders always they used the war and all the people they afraid for this and in my country the learn is very bad because found stupid teacher because always this teacher they thinks they always right 


\section{Text*4}

\section{Living in another culture always carries the risk that} one will be misunderstood, either because of different cultural customs or because of language problems.

Describe an incident that has happened to you since you came to the U.S. in which there was a misunderstanding. Describe what happened and what we can learn from this experience.

It is normal for any one who lives in a differnt cultural customs or with people who speak a different language to have some diffucalty in understand them. There fore he might get in trouble because of his small experience.

I remember an incident which happenen to me and made an impact for me. I had a party with some Amirecan friends. Since Amirecans like to have such a noiesy parties that I didn't famillier with, I suriprisd for their behavior then. They were dancing , drinking, and kissing each other in a strange way. Then, the time came to have our dinner, I sat down to eat. After having the dinner. we sat to talk while the other countinued their crazy dance. I was no longer bear that noise and preferred to escape.

In fact, it is diffcult from a person to get a long on a different cultural unless he or she study it to have enough knoleged. 


\section{$\operatorname{Text} * 5$}

What three things would you like your American classmates to know and understand about your country? Why?

I will write here about first subject or I will answer the first question. The three things I would like my American classmates to know and understand about my country are in the following. First, I want tell my classmates about the farms which we have in Saudi Arabia. There are much farms in Saudi Arabia now. Second thing I want tell my American classmates about my country is industrial we have much factories. The last thing I want tell my American classmates about my country is about the religion of my country. My country religion is Islam. I want tell my classmates about these three things because I want leave my classmates see the basic things we had in Saudi Arabia. 


\section{Text $\div$}

\section{Every country in the world has its share of problems.}

Discuss the two biggest problems your country has. What is your country trying to do about the problems? Do you think you will be able to help in any way? How will you help?

In fact the biggest problems in U.A.E at this time is the war that bettween us and Iraq, because Sadam Hussein started with Kuwait and we know what hapend their from: steel, rap, braking evry thing to kill, so that what hapend to Kuwait then what will hapen to U.A.E if he decided to take it as he toke Kuwait, he did not said just take it he said 'I'll thero a camical bombs on you' he mens us, so emagen what will hapen to the hull area if he theros thos bombs.

From her we say its the biggest problem in U.A.E that small and safe country.

The gaverment made defrent points to face the problem, one of them is the volentyrs sodurs, and more than 30 thausend men have been a volenlyrs sodurs between $15-40$ years old. And I thing evry citesenman in U.A.E must be a volentyr soldur atherwise U.A.E will be the same is Kuwait.

The scecand problem is bringing evrything from the biger conutrys, its OK now for us because we have got the oil or the mony wich we by with evry single thing from them, and lets says the oil will stay for 50 more years so what we'll do after that. From this point we should thing about another power like growing or bild a factoryes 


\section{APPENDIX C}

THE SIX TEXTS WITH

SPELLING ERRORS

HIGHLIGHTED 


\section{Text *1 (12 ERRORS)}

Do you agree or disagree with the following statement? Use specific reasons and examples to support your position.

\section{-Money Doesn't Buy Happiness"}

\section{(Money Desn't buy happiness)}

If anybody think that money can buy happiness I think he is wrong. There is nobody want to sell his happiness and we must consieder these two condition in our mind that everybody in the world wants to live in a good life with no problems in it. There are many people who spend a lot of money just to be in happiness mood.

Firstly, most of the people divid their time between their work and their social life. They don't want to spend all their time in collecting money. They want to enjoy themselfes in their life. They want to be happy with their families and their friends.

Secondly, most of the rich and wealth people spend alot of money just to be happy. You can see them spending their mony to travell to ather countries, makeing parties and going to movies. All these things just to make them happy.

In conclusion, I can't imagen that there is some people who give a chance to the money to buy their happienss. 


\section{Text *2 (32 ERRORS)}

Some people like to travel by plane and others prefer to 80 by car. Which means of travel do you prefer and why?

Some people like to travel by plane but I prefer to travel by car becaws I can see the baerd and the see and the tree and we can stop and enjoy the good wiethar and I prefer the car becaws it take a long taim in travel maor than the plane becaws of that rezaun we can stoop and play and if thers a see we can sweem but in the plane we have to seet in thaer we dont have to move. and when we travel by car we can stoop the car and boot awar food and awar drenk and seat ther antel we want then we can kow mblet aur travel becaws oll of thes rezawn I laik and prefer travling by car. 


\section{Text *3 (26 ERRORS)}

What three things would you like your American classmates to know and understand about your country? Why?

I like in American the first seastam and the secaned free country and the theired study in her because in my country the seastam is very bed and the reson almost the peapole they dan't walk for any seasta $m$ because the leaders very bad and my countrey not free country and no any person he can speack or do any thing the reason is the leaders alwasy they uosed the ower and all the peapole they afread for this and in my country the learn is very bad becaus afouned astuabed teacher because alwasy this teacher they thinks they alwasy riath 


\section{Text *4 (14 ERRORS)}

Living in another culture always carries the risk that one will be misunderstood, either because of different cultural customs or because of language problems.

Describe an incident that has happened to you since you came to the U.S. in which there was a misunderstanding. Describe what happened and what we can learn from this experience.

It is normal for any one who lives in a differnt cultural customs or with people who speak a different language to have some diffucalty in understand them. There fore he might get in trouble because of his small experience.

I remember an incident which happenen to me and made an impact for me. I had a party with some Amirecan friends. Since Amirecans like to have such a noiesy parties that I didn't famillier with, I suriprisd for their behavior then. They were dancing , drinking, and kissing each other in a strange way. Then, the time came to have our dinner, I sat down to eat. After having the dinner. we sat to talk while the other countinued their crazy dance. I was no longer bear that noise and preferred to escape.

In fact, it is diffcult from a person to get a long on a different cultural unless he or she study it to have enough knoleged. 
Text 5 (16 ERRORS)

What three things would you like your American classmates to know and understand about your country? Why?

I will wright her about first subject or I will answer the first question. The three things I would like my American classmates to know and understand about my country are in the fowlloing. First, I want tell my classmates about the farms which we have in Saudi Arabia. There are much farms in Saudi Arabia know. Scande thing I want tell my American classmates about my country is andistral we have much factries. The last thing I want tell my American classmates about my country is about the religen of my country. My country religen is asslam. I want tell my class mates about thes three things becouse I want leav my class mates see the basc things we had in Saudi Arabia. 


\section{Text *6 (48 ERRORS)}

Every country in the world has its share of problems.

Discuss the two biggest problems your country has. What is your country trying to do about the problems? Do you think you will be able to help in any vay? How will you help?

In fact the biggest problems in U.A.E at this time is the war that bettween us and Iraq, because Sadam Hussein started with Kuwait and we know what hapend their from: steel, rap, braking evry thing to kill, so that what hapend to Kuwait then what will hapen to U.A.E if he decided to take it as he toke Kuwait, he did not said just take it he said 'I'll thero a camical bombs on you' he mens us, so emagen what will hapen to the hull area if he theros thos bombs.

From her we say its the biggest problem in U.A.E that small and safe country.

The gaver ment made defrent points to face the problem, one of them is the volentyrs sodurs, and more than 30 thausend men have been a volenlyrs sodurs between $15-40$ years old. And I thing evry citesenman in U.A.E must be a volentyr soldur atherwise U.A.E will be the same is Kuwait.

The scecand problem is bringing evrything from the biger conutrys, its $O K$ now for us because we have got the oil or the mony wich we by with evry single thing from them, and lets say the oil will stay for 50 more years so what we'll do after that. From this point we should thing about another power like growing or bild a factoryes 
APPENDIX D

RATERS' SCORES 
ODD-NUMBERED PACKETS

\begin{tabular}{lcccccc} 
& \multicolumn{2}{c}{ TEXT } & & 5 & 6 \\
RATER & 1 & 2 & 3 & 4 & 5 \\
clean & clean & errors & clean & errors & $\begin{array}{c}6 \\
\text { clean }\end{array}$ \\
1 & & 2 & 1 & 3 & 3 & 4 \\
3 & 3 & 2 & 1 & 4 & 2 & 3 \\
5 & 3 & 4 & 1 & 3 & 4 & 3 \\
7 & 2 & 3 & 2 & 4 & 2 & 3 \\
9 & 3 & 2 & 1 & 3 & 2 & 2 \\
11 & 2 & 2 & 1 & 3 & 3 & 3 \\
15 & 2 & 4 & 1 & 3 & 4 & 3 \\
17 & 4 & 3 & 1 & 5 & 3 & 5 \\
19 & 5 & 3 & 1 & 5 & 3 & 3 \\
21 & 4 & 5 & 2 & 5 & 3 & 4 \\
23 & 2 & 2 & 1 & 2 & 1 & 3 \\
25 & 3 & 3 & 1 & 4 & 3 & 3 \\
35 & 5 & 2 & 1 & 3 & 2 & 4 \\
37 & 3 & 2 & 1 & 3 & 3 & 3 \\
41 & 3 & 2 & 1 & 2 & 2 & 3 \\
45 & 3 & 3 & 1 & 2 & 2 & 3 \\
47 & 2 & 6 & 3 & 4 & 3 & 3 \\
53 & 3 & 2 & 1 & 3 & 2 & 3 \\
55 & 3 & 2 & 1 & 4 & 2 & 3 \\
57 & 5 & 2 & 1 & 3 & 3 & 4 \\
61 & 3 & 3 & 1 & 3 & 2 & 3
\end{tabular}




\section{EVEN-NUMBERED PACKETS}

\section{RATER}

$\begin{array}{lll}2 & 2 & 1 \\ 4 & 1 & 1 \\ 6 & 2 & 1 \\ 8 & 3 & 2 \\ 12 & 4 & 1 \\ 14 & 4 & 2 \\ 16 & 3 & 1 \\ 18 & 4 & 2 \\ 20 & 3 & 1 \\ 22 & 3 & 2 \\ 24 & 4 & 3 \\ 28 & 3 & 2 \\ 32 & 3 & 3 \\ 34 & 4 & 2 \\ 36 & 3 & 4 \\ 38 & 5 & 2 \\ 40 & 3 & 2 \\ 42 & 2 & 1 \\ 48 & 3 & 1 \\ 50 & 3 & 1 \\ 52 & 3 & 1 \\ 54 & 3 & 3 \\ 58 & 3 & 3\end{array}$

TEXT
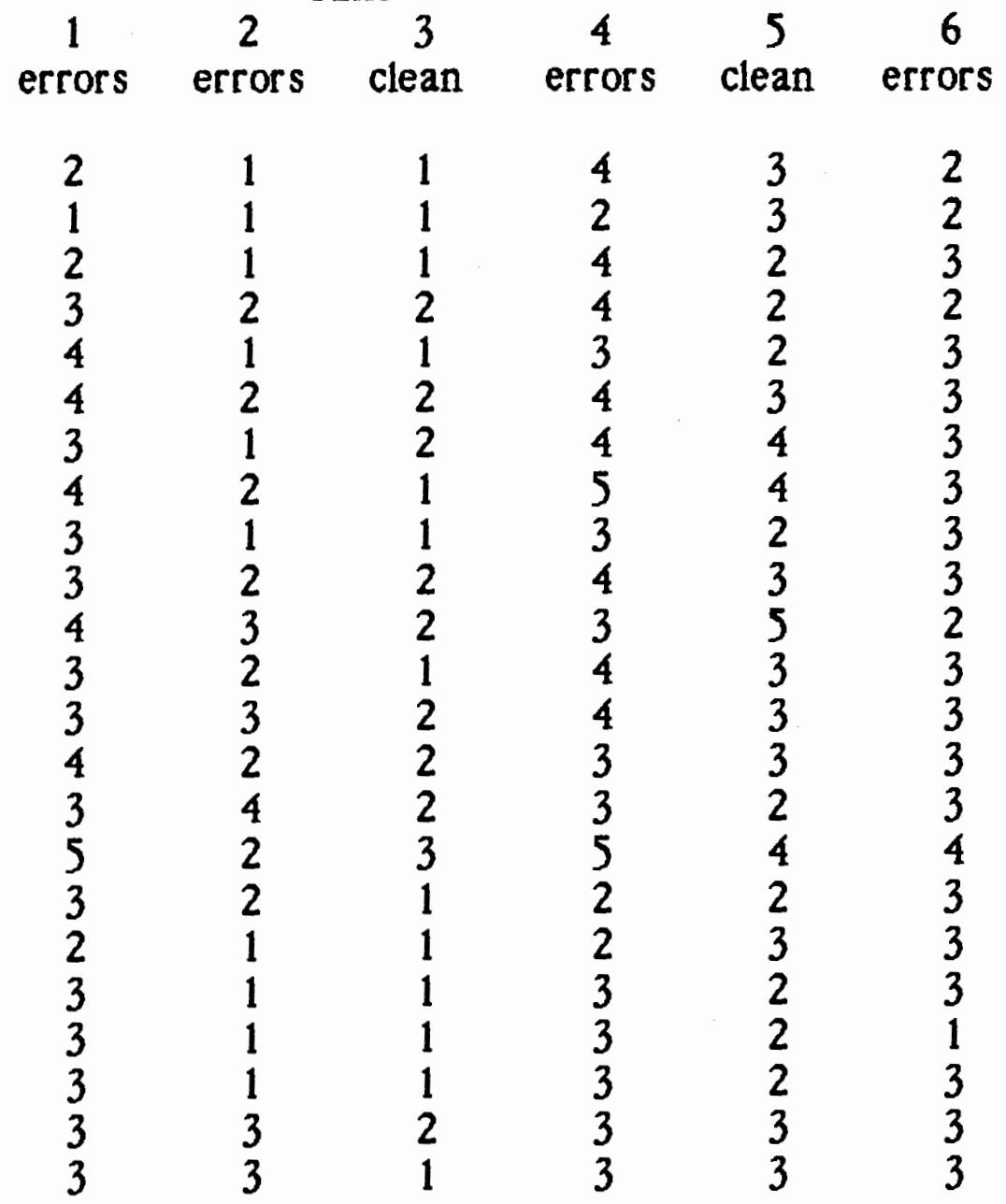


\section{APPENDIX E}

ANNOTATED BIBLIOGRAPHY OF RESOURCES

FOR TEACHING SPELLING 
Allen, R. L., Allen, V. F., \& Shute, M. (1970). English sounds and their spellings: A handbook for teachers and students. New York: Crowell.

A helpful resource for both students and teachers.

Allred, R. (1984). Spelling trends, content, and methods. Washington, DC: National Education Association.

This publication includes a section on teaching methods and some helpful spelling rules.

Barbe, W. B., Francis, A. S., \& Braun, L. A. (Eds.). (1982). Spelling: Basic skills for effective communication. Columbus, $\mathrm{OH}$ : ZunerBloser, Inc.

This collection of works on spelling includes sections dealing with foundations of instruction, classroom practice, and students with special needs.

Childs, S., \& Childs, R. (1963). Sound spelling. Cambridge, MA: Educators Publishing Service.

A good presentation of the spellings of the sounds in English.

Craven, P. R. (1967). Sight and sound: A handbook of spelling. Belmont, CA: Dickenson Publishing Company.

Chapters that would be especially useful include: The dictionary and spelling, Pronunciation and spelling, Prefires and suffixes, and Spelling by rule.

Cummings, D. W. (1988). American English spelling. Baltimore: The Johns Hopkins University Press.

This is an extremely detailed orthographic description, an excellent resource that presents the spelling system of English. This is an outstanding reference for teachers. Information in this book can be used to develop lessons to present to students. 
Hall, R. A., Jr. (1961). Sound and spelling in English. Philadelphia: Chilton Company.

Chapter 4, "Grapheme and Phoneme in English," includes a very useful table showing the graphemic representations of English phonemes. The coverage of the vowels is thorough and could be used in planning spelling lessons.

Hanna, P., Hodges, R., \& Hanna, J. (1971). Spelling: Structure and strategies. Boston: Houghton Mifflin Company.

Part Two includes a plan for developing an eight-level spelling program.

Henderson, E. (1985). Teaching spelling. Boston: Houghton Mifflin Company.

This is a handbook for teachers that inciudes practice exercises and teaching models. It is aimed at native English speakers in the primary and middle grades, but could be adapted for ESL students. A list of vowel sounds and their spelling patterns is included in Appendir 2.

Manning, M. M., \& Manning, G. (1986). Improving spelling in the middle grades (2nd ed.). Washington, DC: National Education Association.

Designed for native speakers in the middle grades, but much of this book could be adapted for ESL students. The section on formal spelling procedures in Part I includes many useful spelling rules. Part Il offers helpful ideas for developing a spelling program, and Part 111 includes spelling activities.

Prator, C. H., Jr., Robinett, B. W. (1985). Manual of American English pronunciation (4th ed.). San Francisco: Holt, Rinehart and Winston.

Lesson 17, "Long and Short Vowels," includes a section on the problems of English spelling. Lesson 18 deals with regular and irregular spellings. 
Venesky, R. (1970). The structure of English orthography. The Hague: Mouton.

Chapter VII includes sections on primary vowel patterns, alternations based upon primary vowel spellings, consonant influences, " $w$ " influences, miscellaneous consonant influences, and secondary vowel patterns.

Wijk, A. (1966). Rules of pronunciation for the English language. London: Oxford University Press.

A thorough presentation of British Standard English pronunciation. 